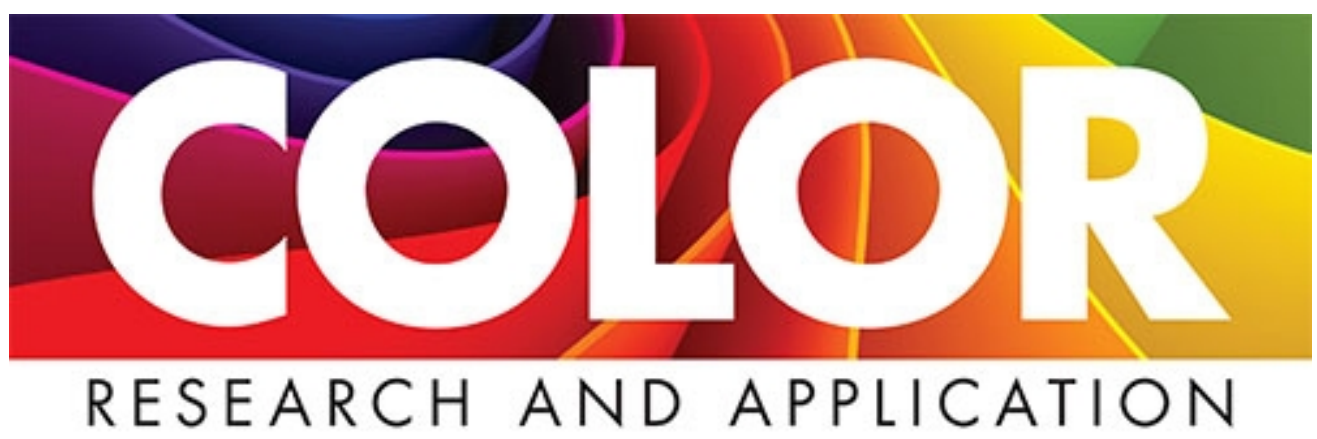

Color determinants of surface stratification

\begin{tabular}{|c|c|}
\hline Journal: & Color Research and Application \\
\hline Manuscript ID & COL-19-059.R3 \\
\hline Wiley - Manuscript type: & Research Article \\
\hline $\begin{array}{r}\text { Date Submitted by the } \\
\text { Author: }\end{array}$ & $n / a$ \\
\hline Complete List of Authors: & $\begin{array}{l}\text { da Pos, Osvaldo; University of Padova School of Psychology, General } \\
\text { Psychology } \\
\text { Vishwanath, Dhanraj; The University of St Andrews } \\
\text { Albertazzi, Liliana; University of Trento, CIMeC (center for Mind/Brain } \\
\text { Sciences); University of Trento, Humanities }\end{array}$ \\
\hline Keywords: & $\begin{array}{l}\text { Color perception, Depth perception, Chromostereopsis, Coplanarity, } \\
\text { Natural lightness }\end{array}$ \\
\hline
\end{tabular}

SCHOLARONE $^{\text {M }}$

Manuscripts 


\title{
Color determinants of surface stratification
}

Da Pos, Osvaldo ${ }^{1}$, Vishwanath, Dhanraj ${ }^{2}$, Albertazzi, Liliana ${ }^{3}$

1 Department of General Psychology, Padova

2 School of Psychology, University of St. Andrews

3 LabExP, University of Trento

\begin{abstract}
Although color plays a crucial role in the demarcation of surfaces in the visual field, its role in depth perception is not well understood. Certain special effects of color on depth perception that arise from optical factors such as chromatic aberration (Chromostereopsis) have been studied, but less is known about the role of perceptual factors of color in determining depth relations. The present study explores the role that the different attributes of color such as hue, chroma and lightness play in the stratification of surfaces in depth. In two experiments subjects manipulated specific dimensions of colors (hue, chroma, lightness and whiteness) while making judgments of coplanarity of either two or more abutting surfaces. The results demonstrate that for surfaces to appear coplanar, their lightness has to be proportional to the natural (intrinsic) lightness of the hues. No meaningful effects of chroma, whiteness or blackness were found in depth stratification. The results suggest a primary role of the natural lightness of hues in depth perception.
\end{abstract}

\section{KEY WORDS}

Color perception, Depth perception, Chromostereopsis, Coplanarity, Natural lightness 


\section{INTRODUCTION}

The perception of surface illumination and coloration (lightness, hue, chroma) is fundamental to our ability to perceive a 3-dimensional visual space partitioned into objects and regions. The perception of brightness gradients (illumination and shading) has long been known by artists as one of the primary means of perceiving 3D object form, and a large body of empirical evidence has investigated and established the role of this dimension in the perception of depth and 3D form in conjunction with other 3-dimensional information. However, very little is known about how differences in surface coloration among different objects and regions contributes to perceived stratification of surfaces in depth. Artists and designers, for example, have been known to use color to enlarge or reduce a space in the visual field or to make things appear closer or further away. A famous example is Turner's painting and technique ${ }^{1,2}$.

The most well-known effect of color in depth perception is Chromostereopsis ${ }^{3-5}$. This is the effect when two surfaces of different specific hues (e.g., red and blue, or, red and green) are adjacent and coplanar to each other; in this case one surface appears to be at a different depth (in front of or behind the other) when viewed with either one or two eyes. The effect has been attributed to chromatic aberration, i.e., arising from optical and physiological factors related to the differential refraction of light due to wavelength ${ }^{6}$. The physiological and optical factors are understood to arise from the displacement of the fovea from the eye's optical axis or to the eccentric location of the pupils $^{7}$ and the Stiles-Crawford effect ${ }^{4,8}$. Generally, the depth stratification under binocular viewing is attributed to the formation of small binocular disparities between the surfaces due to chromatic aberration, while in the monocular condition the surfaces are in focus at different depth planes due to differential refraction at different wavelengths. Some researchers have maintained that the chromatic aberrations are due to global interactive processes ${ }^{9}$. In Chromostereopsis, generally red is seen as closer than green, but a phenomenon of reversal can occur ${ }^{3}$. 


\begin{abstract}
Some researchers have examined the role of color in depth in terms of factors other than chromatic aberration. For example, researchers have examined the role of luminance ${ }^{10-12}$, contrast $^{13,14}$, the distinctness of borders ${ }^{15}$, and the interaction between color contrast and border distinctness ${ }^{16}$.
\end{abstract}

The role of perceptual factors in depth stratification due to color, in contrast to purely optical factors such as chromatic aberration, is particularly interesting and less studied. A relevant study is by Chen and Lin $^{14}$ who examined the role of perceived brightness in judging the depth ordering of surfaces of different hues. Specifically, they measured subjects' judgments of the relative nearness of a pair of circular patches of different hue and brightness. In a pilot phase, they had the subjects judge the brightness of the same patches presented individually.

The main finding was that perceived depth differences were best predicted by brightness differences rather than differences in hue. This suggested a role for brightness as a perceptual factor in color effects on depth. The only effect of hue that was found was that warmer colors tended to be reported as more often appearing in front than cool colors, but only in certain brightness conditions ${ }^{15}$.

Another study examined the role of brightness, hue, and saturation on perceived depth relations ${ }^{17}$. In this study, the perceived relative depth of two hemi-field regions displayed in different colors was measured. It was found that when both surfaces were achromatic, the magnitude of perceived depth was correlated with magnitude of differences in brightness. In the chromatic condition the perceived depth depended on specific hue combinations. When the two hemi fields differed only in saturation, the perceived depth increased with increasing differences in saturation. The effects have been explained in terms of figure-ground differentiation between adjacent regions in the visual field, such that a difference in brightness between two adjacent regions in the visual field forms a figureground reversible pattern, so that the region seen as figure is perceived in front of the region that 
assumes the role of ground ${ }^{17}$. Nevertheless, as mentioned, it is also well known that some colors usually are perceived nearer and other farther from the observer ${ }^{18-21}$.

While the studies by Chen and Lin $^{14}$ and Egusa ${ }^{17}$ measured subjects' perceived depth ordering or depth magnitude, another study examined the role of color in depth stratification by having subjects make coplanarity judgments ${ }^{19}$. Specifically, they used an apparatus where the observer viewed a pair of surfaces rendered in different colors (Yellow, Orange, Red, Purple, Blue, or Green) with a fixed illumination on one member of the pair, and a variable illumination on the other. The task of the observer was either to increase or to decrease the variable illumination until both surfaces appeared to be lying on the same plane, i. e., coplanar.-The illumination of the surfaces was measured with a UDT photometer in units of Lux, from which the luminance of the surfaces could be derived based on the known reflectance of the surface $(L=E * R / \pi)$. An expected outcome of this experiment based on the previous findings ${ }^{14 ; 17}$ is that surfaces should appear coplanar when the brightness is the same. Instead the study by Chen and $\operatorname{Lin}^{14}$ found an interaction between brightness and hue, in that brightness alone did not predict depth ordering. This suggests that there remains an unknown role of hue in depth stratification.

How can this interaction of hue and brightness be understood? One possibility is what is known as the intrinsic or natural lightness of hues introduced by Spillmann ${ }^{22}$ in relation to the issue of color harmony. His theory proposed that surface colors are harmoniously combined if their lightness is in the same ratio as the natural lightness of their hues. The natural lightness of a hue can be deduced from the lightness of its most chromatic nuance. For instance, in Griffin ${ }^{23}$, the psychological structure of the Basic Colour Terms (BCTs) is represented in a configuration where the nodes on the color space skin indicate 'best exemplars' (prototypes, focal colors) of the corresponding color categories, including R, G, B, Y, and P, and the node height along the vertical dimension reflects the natural lightness of the hue. The same organization can be seen in the 
Munsell color tree where the maximally chromatic colors lie at different heights on the Value scale depending on their hue. According to Spillmann ${ }^{22}$ a combination of blue and green should appear agreeable if the lightness of the blue nuance is lower than that of the green nuance, because the natural lightness of blue is lower that the natural lightness of green. This theory was supported by a series of studies ${ }^{24-28}$. The intrinsic lightness of a hue is defined on the basis of the optimal or most representative color of that specific hue (highest chroma). Note that this concept of intrinsic lightness derives from phenomenological observation, and it is to be distinguished from the fact that any given color, for a given illumination, has different lightness as a result of the interaction of the spectral composition with receptor. Natural lightness of hues, as previously mentioned, is an important characteristic of colors which also affects color combination pleasantness, and the apparent fluorescence of some colors ${ }^{25}$.

When the data from da $\operatorname{Pos}^{19}$ were reconsidered in light of the concept of intrinsic lightness, they suggested that further studies about the role of color in depth stratifications may benefit from a specific focus on the lightness dimension. Specifically, a reanalysis suggested that, in normal viewing conditions, the lightness (the psychological attribute that is a counterpart to the physical attribute reflectance) of perceptually coplanar surface colors depends on the natural lightness of their hue; that is, the ratio between the lightness of coplanar colors corresponds to the ratio of the natural lightness of their hues.

The reason we are interested in lightness and not in brightness (or in luminance) is that lightness is a direct characteristic of a surface color, while brightness (and luminance) depends also on the illumination, which is not a property of the surface. Brightness is therefore not a characteristic of the specific surfaces while lightness is a surface characteristic independent from the illumination. The present study aimed to examine this relationship between intrinsic lightness of hues and the perception of coplanarity (stratification) in more detail. 
One should keep in mind that lightness is a function of the surface reflectance under the assumption that white has the highest reflectance in the visual field. According to Gilchrist et $\mathrm{al}^{30}$, perceiving white does not necessarily imply a reflectance factor of $100 \%$ as assumed by the Retinex theory. Surfaces reflecting 50\% can be perceived as white if their luminance is the highest in the visual field). This means that the area with highest luminance appears white, and as an idealization, this can be assumed as reflecting $100 \%$, as it approximately happens in most real cases, in agreement with the Retinex theory.

In this study we deal with colors which appear surface and uniformly illuminated.

\section{THE STUDY}

In our study, we tested which color conditions are necessary for perceiving different colored surfaces as appearing on the same fronto-parallel plane. As is well known, if a colored surface is overlapping and partially occluding another differently colored surface, the visual margin (contour) separating the two belongs to the occluder and defines it closed boundary. The occluded (background) surface does not appear closed by that contour, but is perceived amodally continuing behind the occluding surface ${ }^{31,32}$. In contrasts, when the two surfaces are perceived lying on the same plane, the margin or contour (where the two join/abut) assumes a double function belonging simultaneously to both surfaces ${ }^{33}$. Therefore, the perceived stratification of the two surfaces operates in parallel with the perceptual attribution of the dividing border.

An interesting case $\mathrm{e}^{34,35}$ is when more than two surfaces are contiguous, for example, when a circle is divided into four or more differently colored sectors. In this case, one may ask which margin(s) plays the major role in the whole configuration, and consequently on which plane(s) the surfaces are seen. In our study, to analyze these issues, the characteristic of the margins have been designed to facilitate the formulation of the instructions given to the participants to perform the task. The observer has to decide whether two abutting surfaces appear to be on the same plane (or if one 
appears closer than the other) by specifically considering the status of dividing margin (see details below).

In the first experiment we tested an elliptical configuration horizontally divided in two parts by a wavy line. In the second experiment, we increased the complexity of the task by having multiple coloured surfaces in a circular configuration and having the observer judge coplanarity locally between abutting pairs of coloured surfaces and globally for the whole configuration.

In these two experiments we examined the role of different dimensions (chroma, lightness) for the perception of surface coplanarity. Additionally, the dimensions of whiteness and blackness (constructs as defined in the Swedish Natural Color System-NCS) were also tested ${ }^{36}$.

According to Hering's view, the perceptual color attributes whiteness and blackness can be measured on the basis of their similarity to White and Black, the two achromatic unique colors of the NCS. Therefore the 0 (White)-100 (Black) scale specifies the percentage of similarity of a color to Black (for instance, N7000 denotes a neutral color with a 70\% resemblance to Black and a $30 \%$ resemblance to White, the last two digits denote the chromaticity of the color, which in this case is null).

The reference system for color used in the design of this research is the Natural ColourSystem ${ }^{37}$ and the Munsell System according to the CIELAB Transformation. We used the NCS because it represents, in a spatial form, the inter-relationships between colors as they are qualitatively perceived by humans. The NCS is built on the direct evaluation of colors in relation to the extent of their resemblance to the unique colors, which play a primary role in Hering's color theory ${ }^{38}$. The NCS is organized by considering the six unique or elementary colors (four chromatic unique colors: red, yellow, green and blue, and two achromatic ones: white and black) as the primitives. All other colors resemble the primitives to different degrees. The NCS system specifies that any 
chromatic color can resemble the two adjacent chromatic hues but not non-adjacent and incompatible hues (for instance, yellow-red or yellow-green are adjacent and compatible, but not yellow-blue, which are opposite and incompatible). At the same time, any color can resemble the two achromatic colors (white and black), which, though unique, are compatible unlike the other chromatic opponent pairs (i.e., a shade of both white and black can be perceived in a single color). As there are many different stimuli which trigger the impression of an elementary color, especially green $^{39}$, so there are many stimuli which can trigger the impression of white. This distinction between white stimuli and perception of white is relevant to understand the concept of whiteness in the NCS, which concerns the subjective perception independently of the physical stimulation. In our experiments perception of white was produced according to the CIE colorimetric specification ${ }^{40}$, that is 'white' $=$ achromatic stimulus $\left(\mathrm{x}=\mathrm{x}_{\mathrm{n}}, \mathrm{y}=\mathrm{y}_{\mathrm{n}}\right)$ at maximum lightness $(\mathrm{Y}=100)$ under the illuminant D65. We are aware that not all people will have the same perception of white following that stimulation, but the perceptual result is enough general for the purpose of our experiment. The NCS is designed to include all perceivable surface colors such resemblance to one or two unique chromatic hues and the two achromatic hues (white and black) is the entire color denotation $(100 \%)$. The nature of the NCS system, in that it is based on similarity, makes it essentially different from the Munsell system which is based on differences between adjacent colors. The Munsell system's most important property is the representation of colors organized in equal difference steps, and the first role of CIELAB, which was developed along its line, is to measure color differences.

Lightness is not used as a variable for the construction of the NCS, and the representation of lightness in the NCS color atlas must be derived post hoc in order to relate it CIELAB ${ }^{37}$. The lightness of each hue can be represented in the NCS color space by lines converging in a point external to the NCS triangle; this point is different for the different hues. 
We aimed to examine how all the different parameters of color (hue, lightness, chroma), including the NCS-specific constructs of whiteness and blackness, could potentially contribute to the stratification of surfaces into figure and ground. The rationale for studying whiteness and blackness as defined in the NCS system is that under this system, they represent primitive perceptual qualities of colors and therefore may play a role that is distinct for that of lightness.

While the current study incorporates all the aforementioned attributes deriving from the NCS, it is operationally easier to produce color variations using the CIELAB color system since the mathematical function linking stimulation to CIELAB is well determined, while it is not as much for the NCS; the differences between corresponding colors in the two systems are negligible for the purpose of this research although the NCS is not a linear transformation of CIELAB ${ }^{42}$. Therefore, variations in whiteness and blackness are performed in CIELAB by using an algorithm developed by the first author that produce colors along the shortest line from the given color either towards white or towards black. This change also affects the NCS attribute of chromaticness (and the corresponding CIELAB attribute, chroma) $)^{41}$.

\begin{abstract}
Note that whiteness and blackness cannot simply be reduced to the sum of lightness $\left(\mathrm{L}^{*}\right)$ and chroma $\left(\mathrm{C}^{*}\right)$ because, as previously mentioned, they are perceptual attributes based on similarity and not differences between adjacent colors as in CIELAB and Munsell. Therefore, the solution of varying the CIELAB L* and $\mathrm{C}^{*}$ in combination is not a theoretical choice but a practical device to approximate variations in the place of Whiteness and Blackness.
\end{abstract}

\title{
INSERT FIGURE 1 ABOUT HERE
}

Also, variations of $\mathrm{L}^{*}$ alone are not easy to show in the $\mathrm{NCS}^{37}$ but are quite simple to show in CIELAB ( Figure 1, right). The vertical line in the central Figure 1, passing through a second 
given color (black diamond), represents variations of $\mathrm{W}, \mathrm{S}$, and $\mathrm{L}^{*}$ at constant chromaticness (counterpart of $\left.\mathrm{C}^{*}\right)$; the variations in $\mathrm{L}^{*}$ can be linearly represented in a CIELAB $\mathrm{L}^{*} \mathrm{C}^{*}$ diagram (right) by a vertical line where $\mathrm{L}^{*}$ can be changed vertically at constant $\mathrm{C}^{*}$, and variations in WS can be linearly represented in a CIELAB $\mathrm{L}^{*} \mathrm{C}^{*}$ diagram (left) by lines converging in $\mathrm{W}$ and $\mathrm{S}$. The definition of lightness, brightness, chroma, chromaticness, and colorfulness can be found in the CIE International Illumination Vocabulary) $)^{42}$.

\section{METHODS}

The research was performed in two separate experiments with increasing complexity of the stimuli". To explore the role of different hues we selected the colors Yellow, Red, Purple, Blue, and Green in order to have a sufficient variety of colors but at the same time keeping the number of test trials manageable. In the first experiment, the colors were presented in pairs on the two sides of an ellipse divided horizontally by a wavy contour. In the second experiment the colors were the same as in the previous experiment, but instead of the ellipse, the stimulus was a larger circular disk divided into 5 equally large sectors by wavy radii. The participant's task was to adjust one of the properties of interest (lightness or whiteness/blackness), while the hue was kept fixed, until the surfaces appeared coplanar.

\subsection{Participants}

All participants (84 in total for the two experiments) were students recruited by e-mail at the University of Trento, Italy. The experiments complied with the ethical guidelines of the University of Trento. Upon request, the participants were issued a certificate for the award of university coursework credits. The information collected from participants prior to the experiment pertained to nationality (all the subjects were Italian), visual acuity (to confirm normal or corrected-to-normal vision), color vision (assessed by the Ishihara test, 38-plate edition) and familiarity with color 
conceptually or practically (as acquired in work, artistic or educational settings). The only exclusion criterion was defective color vision. All the subjects signed an informed consent form.

\subsection{General Testing Protocol}

The distance from the center of the screen to the eye was about $65 \mathrm{~cm}$ and the presentation was performed with binocular vision. Chin supports were not used, but during each session the postures of the participants were checked by the experimenter and corrected if their chests approached the screen or their backs were hunched.

\section{EXPERIMENT 1}

\subsection{Methods}

\subsubsection{Materials}

The laboratory (CiMEC, Trento) had controlled lighting conditions (ca. 10 lux, on average, provided by a halogen lamp). The stimuli were presented on a Quato Display 242 TFT screen $(52.3 \times 32.6 \mathrm{~cm})$. Monitor calibration was performed with the IntelliProof 242 excellence software supplied by the Quato company using the Silver-haze-pro \& DTP94-LCD device. The calibration guaranteed a white D65, a 2.2 gamma, $120 \mathrm{~cd} / \mathrm{m}^{2}$ luminance, at maximum contrast. The monitor was recalibrated at the beginning of each session.

\subsubsection{Stimulus}

In the first experiment, we tested the role of whiteness/blackness (Exp. 1A) and lightness (Exp. 1 B) in surface stratification. The target stimulus was an ellipse ( $7^{\circ}$ wide, $5^{\circ}$ high) displayed at a distance of $65 \mathrm{~cm}$ (see Figure 2). The target stimulus was presented over an achromatic checkerboard background of light and dark grey squares to control for the possibility that a single uniform grey background could interact with the choice of the closer figure due to differences in contrast with specific settings of the target stimulus that will be caused by uniform background. 
The elliptical stimulus was divided into two asymmetric colored regions with a demarcating wavy boundary dividing the figure along the horizontal. This choice was based on the fact that any upper/lower visual hemifield biases will likely be more consistent across observers that any left/right biases, which have greater individual and cultural variation ${ }^{43,44}$. Furthermore, any upper/lower hemifield biases were controlled by presenting all the color pairs twice in inverted positions, so that each adjustable color appeared on both side of the ellipse. The wavy contour was chosen to increase the length of the boundary between the two colors so that it was longer than the external boundary between each sector and the background. This was done to minimize the effect of the background on the assumption that spatial interaction between colors depends on the length of the separating border (as, for example, in the filling-in effect of the watercolor illusion which is stronger with long wavy contours ${ }^{45}$ ).

FIGURE 2. about here

The five colors tested (Yellow, Red, Purple, Blue, and Green, see details in Table 1) were chosen to correspond as far as possible to the 3040 NCS nuance. Selecting these hues allows a larger range of adjustments in lightness or whiteness/blackness while keeping the color chromatic (i.e. not veering too far into greys). In total, twenty pairs of colors were presented in a randomized order.

\subsubsection{Color adjustment protocol}

The adjustment to either lightness or whiteness/blackness was made following CIELAB space directions, as previously indicated. In the case of lightness only, hue and chroma were fixed while CIELAB lightness was varied (Exp. $1 \mathrm{~A}$; figure 1 right side). In the case of chroma, hue and lightness were fixed while CIELAB Chroma varied. For whiteness (blackness) both lightness and chroma (in CIELAB space) was varied (Exp. 1 B; figure 1 left side). Note, CIELAB chroma 
roughly corresponds to the NCS chromaticness. An algorithm set the appropriate RGB values for the display based on the alterations to variables in the CIELAB space. Furthermore, for adjustments in whiteness (blackness) the starting colors (before adjustment) were taken at higher chroma (see Table 1 left) to allow for a larger interval between the initial color and $100 \%$ whiteness (or blackness) (see Figure 1). In contrast, when the variation was made in lightness, the starting colors were of a lower chroma (Table 1 right) to increase the lightness range for which observers could perform the adjustments.

TABLE 1 about here

\subsubsection{Task and procedure}

After the presentation of the test image the participants had to immediately state verbally which surface appeared in front. They then had to change the color of the adjustable segment until the two segments of the oval were perceived to be coplanar (i.e., neither appeared as lying above or below the other, or, closer or more distant from the observer). As a perceptual hint to decide which surface appeared in front, participants were asked to imagine inserting a knife under each surface at the separating boundary with the aim of lifting it up. The one for which it seemed more perceptually intuitive to do this was the one in front. The point of perceptual coplanarity was when both surfaces seemed to have the same likelihood of being chosen based on this criterion.

To vary whiteness/blackness of colors (Experiment $1 \mathrm{~A}$ ), the participants could use four buttons, placed in the upper part of the screen, by which whiteness could be increased or decreased by small or large steps $(+5 w+1 w-1 w-5 w)$. Similarly, another four buttons could be used to vary blackness $(+5 s+1 s-1 s-5 s)$. Changes were constrained along the directions from the original colors either towards white or towards black as approximated in the CIELAB system (Figure 1). 
To vary the lightness of colors (Experiment 1 B) participants used only four buttons only $(+5+1-1$ 5); changes were constrained along the vertical L* direction in the CIELAB color space.

\subsubsection{Participants}

39 participants volunteered for the first experiment: 29 women and 10 men (mean age: 22.5; standard deviation: 3.8$)$.

\subsection{Results}

No notable differences were found between the adjusted colors in the upper part of the ellipse and those in the lower part. T-tests for all 20 pairs, for each of the 3 CIELAB parameters L*a*b* revealed a significant difference for only one pair out of $20(p<0.044)$ without including any correction for multiple comparisons and therefore we conclude that there was no meaningful effect of orientation.

Table 2 displays the result of the individual adjustments to lightness and whiteness for the 20 pairs of colors used to make the coplanarity judgement. Tabulated values show the adjusted values of $\mathrm{L}^{*}$ for both the lightness adjustment (where $C^{*}$ was fixed) and the whiteness (W) adjustment in the other conditions. These data served to derive both $C^{*}$, which was either fixed (in the lightness adjustment condition) or changing in parallel with $\mathrm{L}^{*}$ (in the whiteness adjustment condition), and $\mathrm{W}$, which was found in a personal dataset containing the CIELAB values of all the colors of the NCS atlas (2nd edition) ${ }^{40}$. Tables 3, 4, and 5 (Supplementary materials) show the color differences between the adjustments of one color and those of all other colors $\left(\Delta \mathrm{L}^{*}, \Delta \mathrm{C}^{*}, \Delta \mathrm{L}^{*} \mathrm{C}^{*}\right)$.

TABLE 2. about here

FIGURE 3 about here 
In the lightness adjustment task, the adjusted $\mathrm{L}^{*}$ of the variable colors is almost independent of the fixed colors, and is very high for yellow, lower for green, blue, purple, and red, in that order (Figure 3, left). A similar result is also found in the case of the whiteness adjustment. The value of $\mathrm{L}^{*}$ at coplanarity (resulting from the whiteness adjustment) decreases from yellow to red again almost independently of the contiguous fixed colors (Figure 3, right). In the case of variations of $\mathrm{L}^{*}$ at constant chroma (left) the adjusted $\mathrm{L}^{*}$ of red and purple are very close to each other, while the adjusted $\mathrm{L}^{*}$ of red is lower than that of purple when the whiteness adjustments was done with variable chroma (right). The colors used in this experiment were chosen to be good exemplars of the five hues yellow, red, purple, blue and green, and the sequence of adjusted L* agrees with the intrinsic lightness of their hues quantified in the form of centroids' lightness of their color category $46-49$.

We further examined the data in the whiteness adjustment task, but now in terms of the overall value of whiteness, rather than the component lightness $\left(\mathrm{L}^{*}\right)$ and chroma $\left(\mathrm{C}^{*}\right)$. As the adjustments and stimulus settings were in form of $\mathrm{L}^{*}$ and $\mathrm{C}^{*}$, the adjustments in whiteness could be derived by finding the colors of the NCS Atlas 2nd edition which were closest to the adjusted colors specified in the CIELAB system. The approximations were rather good, with deviations spanning from 3.6 to $5.3 \Delta \mathrm{E}($ mean $\Delta \mathrm{E}=4.6, \mathrm{SD}=0.48)$.

FIGURE 4. about here

Figure 4 shows that red and yellow are adjusted to a low whiteness value while purple to a high whiteness value, with green and blue in-between. This ordering of the hues does not seem to follow the ordering of any known attributes of color. We conclude, therefore, given the similarity in the order of settings in $\mathrm{L}^{*}$ for both the lightness and whiteness adjustment task, that the primary 
systematic determinant of coplanarity in the whiteness task is the lightness, but with a different quantitative outcome due to the simultaneous change in chroma that the whiteness adjustment produces.

FIGURE 5. about here

Figure 5 shows the correlation between the $\mathrm{L}^{*}$ values obtained in lightness task (Y-axis) and the whiteness task ( $\mathrm{x}$-axis) showing a clear correlation in $\mathrm{L}^{*}$ setting in the two task and again revealing the order of the setting from low to high lightness to generally follow the ordering of the natural lightness of the hues (in the order Y G B P R). The last position of red conforms with the general opinion that red usually appears closer to the observers than the other colors ${ }^{50}$ for the reason that usually it is observed at higher lightness. Moreover, it is also in agreement with the previous research performed in completely different conditions ${ }^{19}$.

As the slope of the regression lines in Figure 5 shows, the range of values for adjustments in whiteness/blackness is much larger than for adjustments in lightness (26.8 vs 13.4), although the mean lightness of the adjusted colors is similar when adjustments are performed in whiteness/blackness and when performed in lightness only $\left(\mathrm{L}^{*}=57.3 \mathrm{vs} \mathrm{L}^{*}=58.6\right)$. This might be due to the role of chroma, as in the Helmholtz-Kohlrausch-Boswell effect ${ }^{51}$, where increases in whiteness are accompanied by decreases in chroma (except for green). This reduction in chroma might be balanced by a larger increase in lightness to reach coplanarity.

The role of chroma in the coplanarity judgement was difficult to interpret in this experiment as the adjustments to chroma were not done independently but were constrained by the nature of the allowed adjustments in whiteness and blackness. These adjustments had to occur from the given color either towards white or towards black, with the consequence that chroma decreases not 
only by increasing whiteness but also by increasing blackness. This is shown in the few examples of adjustment in Figure 6. It shows that $C^{*}$ decreases both when $L^{*}$ increases (towards White) and when it decreases as well (towards Black). Although the changes in chroma were primarily due to changes in the stimulus, as shown in Figure 1 left, they also depend on perceived changes in lightness/blackness as described by Bimler et $\mathrm{a}^{52}$. In that case, a colored central disc appeared desaturated when it was affected by both whiteness and blackness induction from a neutral anulus. The design of the current experiment was therefore not ideal for making significant inferences about the role of chroma.

FIGURE 6. about here

Indeed, the adjusted chroma turns out to be almost the same for each fixed color in comparison to all other adjustable colors (Figure 7) for each of the five colors adjusted in whiteness/blackness. Note that, except for green, the starting chroma of the adjusted color is always higher than the adjusted one regardless of the chroma or lightness of the fixed color. Therefore, we conclude that a special relationship between lightness and hue is the most relevant color characterization which determines depth stratification, in the sense that colors can be perceived lying in the same plane when their lightness ratios follows the natural lightness of their hue, or the corresponding lightness of their color category centroids.

FIGURE 7 about here

It is worth noticing that at the beginning of each trial participants were asked to state which of the two colors in the display appeared in front. The answers were quite variable. Fewer than one third of the selections were contrary to what we might have expected from the results of color adjustment. This outcome contrasts with the relatively low variability in the adjusted colors 
(variability coefficient was around $0.11-0.13$ ), considering that all participants were mostly naïve in the field of color as well as the experimental procedure. It is possible that the attention required to adjust the colors makes participants more precise and reliable, compared to their initial judgments in a few seconds after the initial presentation. Another possibility that cannot be ruled out is that the first impression and attention-guided observation might lead to different kinds of perception.

\section{EXPERIMENT 2.}

The second experiment aimed to replicate the first experiment on lightness, whiteness, blackness in surface color stratification but using a more complex figural configuration as well as a slightly different task (adjustments of multiple colored surfaces on a single stimulus).

\subsection{Methods}

\subsubsection{Participants}

There were total of 52 participants: 19 males (mean age: 31, 7; standard deviation: 13, 5); 33 females (mean age: 27, 8; standard deviation: 12,0).

\subsubsection{Materials}

The experiment (Exp. 2) was conducted in the LabExP of The University of Trento which had constant and controlled lighting conditions (ca. 10 lux on average in the room provided by a halogen lamp). The colors were produced on a Eizo Color Edge monitor, model number CG276 P7N OFTD1846 75Q with a screen dimension of $68 \times 27 \mathrm{~cm}$ and a resolution of $2560 \times 1440$. The software used to calibrate the monitor was Color Navigator 6 v.6.4.0.5 by Eizo Corporation. The calibration guaranteed a white D65, a 2.2 gamma, $120 \mathrm{~cd} / \mathrm{m} 2$ luminance, at maximum contrast. The monitor was recalibrated at the beginning of each session. 


\subsubsection{Stimuli}

The colors and tasks of the participants were the same as the previous experiment, but instead of the ellipse, the stimulus was now a larger circular disk $\left(10^{\circ}\right.$ at $65 \mathrm{~cm}$ viewing distance $)$ divided into 5 equally sized sectors by wavy radii (see Figure 8). Custom computer code changed the RGB values of the screen colors to produce colors according to the experimental requirements.

FIGURE 8 about here

At the start of the trial, one sector was always the same green color, while the other four sectors were of a different (random) grey tone (left, Figure 8) and could be adjusted by changing either lightness (keeping chroma constant; Experiment 2 A) or changing the whiteness/blackness (Experiment 2 B). In the latter case lightness and chroma changed together, depending on the experimental requirements.

The sample colors shown in the right of Figure 8 represent an example of the final adjusted colors, either when the adjustment was in $\mathrm{L}^{*}$ at constant chroma, or when it was in $\mathrm{L}^{*}$ with variable chroma.

\subsubsection{Task and procedure}

The task of the participants was to modify the color of four quadrants of the circle (the fifth was fixed) using sliders located on the left side of screen. The initial displayed showed the fixed green sector and the other sectors were displayed in greys (Figure 8, left). The sector to be adjusted was selected by placing the cursor on the associated slider, which would then cause the color of the associated sector to appear at a random value of the attribute to be adjusted (indicated by the length of the yellow bar in the slider). This initial value is chosen from a 'prefixed range' such that all 
changes are linear inside the two extremes of the range (for the whiteness adjustment, between the given color and white; for the lightness adjustment, between the lowest and the highest possible $\mathrm{L}^{*}$, both at the same chroma. By adjusting the yellow bar, the participant can choose the color in this predefined range that meets the coplanarity requirement (Figure 8, right).

As in the first experiment, the participants performed two tasks, adjusting either the whiteness (the actual change was of $\mathrm{L}^{*}$ and $\left.\mathrm{C}^{*}\right)$ or the lightness of the colors $\left(\mathrm{L}^{*}\right)$, in two different runs.

The task in both was to make each sector appear coplanar to all the others (i.e., none of them should appear in front of or behind another, or above or below the other). The same instructions as experiment 1 were given regarding the coplanarity judgement. Participants could modify each color as many times as they wanted. However, before taking the final decision, they were required to observe the circle globally without focusing on a specific quadrant, to confirm that all sectors, considered as a whole, appeared to be on the same plane. If not, they were required to re-adjust any of the colors that did not appear coplanar. When participants were satisfied that all sectors appeared as coplanar as they possibly could, the results were recorded in term of $\mathrm{L}^{*} \mathrm{a}^{*} \mathrm{~b}^{*}$.

\title{
5.2 Results
}

Table 3 show the main results, in terms of adjusted $\mathrm{L}^{*}, \mathrm{C}^{*}, \mathrm{~W}$ for the four variable colors $(\mathrm{Y}, \mathrm{R}, \mathrm{P}$, B) of the second experiment. Green was always fixed. The left half of the table show the results for the whiteness/blackness adjustment when $\mathrm{L}^{*}$ and $\mathrm{C}^{*}$ were adjusted at the same time $\left(\mathrm{L}^{*} \mathrm{WK}\right.$, $\mathrm{C}^{*} \mathrm{WK}, \mathrm{WWK}$ ); the right half of the table show the results when $\mathrm{L}^{*}$ was adjusted at constant $\mathrm{C}^{*}$.

TABLE 3 about here

\author{
5.2.1 Role of L*
}


The main results of this second experiment (Figure 9) show that $\mathrm{L}^{*}$ at coplanarity increases from red to yellow following the hue circle in a clockwise direction in agreement with the results of the previous experiment.

FIGURE 9. about here

Figure 10 shows a plot showing the correlation in setting of $\mathrm{L}^{*}$ in the whiteness $\left(\mathrm{L}^{*}\right.$ and $\mathrm{C}^{*}$ vary) and lightness only task ( $\mathrm{L}^{*}, \mathrm{C}$ constant). As in Experiment 1, there is a clear correlation in setting and the order of the hues in terms of adjusted lightness is the same as found in the previous experiment.

FIGURE 10 about here

In a plot of $\mathrm{L}^{*}$ at constant $\mathrm{C}^{*}$ vs $\mathrm{L}^{*} \mathrm{WK}$ (Figure 11 ) the adjusted $\mathrm{L}^{*}$ appears varying in the same direction of the inherent lightness of the hues, which in turn conforms to the lightness of the centroids of the corresponding focal colors. However, as in the first experiment, the results viewed in terms of whiteness do not reveal any systematic patterns in the coplanarity setting (Figure 11) as a function of the four variable colors. Also, Figure 12 show the results of $\mathrm{W}_{\mathrm{L} * \text { var.C*var. }}$ plotted as a function of $\mathrm{W}_{\mathrm{L} * \text { var.C*const }}$, which shows no correlation in the settings when considered in terms of whiteness (W).

FIGURE 11. about here

FIGURE 12. about here 
The difference between Experiment 2 and Experiment 1 is essentially in the procedure. All possible color pairs were tested individually in the first experiment, while in the second, all colors are present at the same time, abutting each other in random order. In both experiments the task was to make the abutting sectors appear coplanar; two in the first experiment, five in the second. The same color is adjusted four times in Experiment 1 and only once in Experiment 2, although in the second experiment more adjustments are needed for the same color depending on the global appearance of the five sectors of the circle. The results of the two experiments are very similar, with similar ordering and slope of lightness values. Both agree well with the previous initial research ${ }^{20}$ showing that the lightness of coplanar colors is proportional to the natural lightness of their hues.

\subsubsection{Role of chroma (C*)}

Results of the L* adjustments (Figure 13) plotted as a function of chroma $C^{*}$ in the whiteness judgement confirms that colors are ordered in the same way as in the previous experiment with respect to lightness ( $\mathrm{Y} \mathrm{G}, \mathrm{B}, \mathrm{P}, \mathrm{R}$ ). However, the ordering of $\mathrm{C}^{*}$ shows no pattern that suggests any role of chroma.

FIGURE 13 about here

FIGURE 14. about here

Figure 14 shows that, as in Experiment $1, C^{*}$ decreases both when $L^{*}$ increases (towards White) and when $\mathrm{L}^{*}$ decreases (towards Black) which makes interpretation difficult especially as it appears that the adjusted chroma in the whiteness judgements depends on the initial values of the presented color. 


\section{GENERAL DISCUSSION}

Our study investigated color attributes that play a role in determining the perceived stratification of surface in depth solely on the basis of color. Based on previous studies, we hypothesized a role for lightness and the NCS construct of whiteness/blackness. These attributes of color were varied by transforming adjustments in each attribute space to CIELAB coordinates, $\mathrm{L}^{*}$ and $\mathrm{L}^{*}+\mathrm{C}^{*}$ respectively.

In two experiments using different stimuli and different coplanarity judgements (either 2 or 5 adjacent surfaces), we found a necessary and sufficient role of lightness. Specifically, the results indicate that in order for surfaces to appear coplanar, lightness has to be proportional to the natural lightness of their hue, or to the lightness of the centroids of their color category ${ }^{49}$.

This is consistent with subjective reports of some of the participants. Some pairings of colors that were reported by the participants as difficult to achieve coplanarity involved red as one of the colors (the combinations yellow/red, green/red, blue/green). Specifically, in the first experiment, in a few individual cases, the combinations containing red as the fixed color were reported to be particularly difficult to perform. These participants reported that none of the allowed modifications were able to bring the other color in the foreground. Indeed, the red as a fixed color was presented with a relatively high luminance, hence it would have been difficult to find a luminance of other colors that might have made it appear on the same plane. This is verified by the fact that in the evaluations given by the subjects relatively to in front/behind, the red is seen behind the yellow, but often in front of the other colors. In the future, an option should be added to the response to allow subjects to express their impossibility of fulfilling the task.

While the current study was done simulating surfaces on a digital display device, a potential question is whether the same results would hold for real surfaces. A previous study where real 
surfaces and real illuminating devices were used found results consistent with those reported here ${ }^{19}$. It would be useful to confirm if the present results can be replicated with real surfaces with equivalent stimulus configurations in order to firmly establish the unique role of lightness in depth stratification

We did not find a unique contribution to the perceived depth stratification of the whiteness/blackness manipulation, which involved simultaneous adjustments to both lightness and chroma $\left(\mathrm{L}^{*}+\mathrm{C}^{*}\right)$. The results show that the setting of $\mathrm{L}^{*}$ considered separately in the whiteness adjustment was well correlated to the $\mathrm{L}^{*}$ of the lightness-only adjustment. However, there was no correlation with the change in chroma $\left(\mathrm{C}^{*}\right)$ or any noticeable pattern to the setting at coplanarity when considered only from the standpoint of chroma. The fact that the $\mathrm{L}^{*}$ settings for the whiteness manipulation varied over a larger range compared to the $\mathrm{L}^{*}$ only manipulation (e.g., Fig 14) suggests that the whiteness manipulation was also simply a function of perceived lightness with the added complication that simultaneous changes in chroma had to be further compensated for by larger adjustments in $L^{*}$ in the whiteness task. The extra increment of $L^{*}$ found when $C^{*}$ was also changing can be explained by the Kohlraush-Helmholtz effect ${ }^{46}$. Nevertheless, Figures 6 and 14 show that decrements of $\mathrm{L}^{*}$ can also be sometimes accompanied by decreasing chroma. Therefore, further research is needed as regards the role of chroma in depth stratification. In the first experiment, we expected the presence of a potential bias towards perceiving the bottom half of the figure as appearing in the foreground because of the potential interference of semantic factors. This tendency appeared during the experiment, as confirmed by the comments of the participants themselves. For example, when the color blue was presented in the top half of the ellipse, it was often assimilated to the sky and thus might have appeared in the background regardless of the other hue below ${ }^{53}$. In the same way, yellow in the bottom half of the ellipse might have resembled a beach, and so on ${ }^{54}$; similar observations were performed by Kanizsa ${ }^{31}$ in terms of anisotropy of the visual space. We did however control for this potential bias by presenting all pairs of colors in two positions, and no systematic effect of position was found overall in 
Experiment 1. Moreover, this kind of bias is, by design, absent in the second experiment, in which we found similar results to experiment 1 . So, while we can exclude the role of such semantic biases in the main finding here, these types of biases do likely add a further degree of complexity to role of color in depth stratification.

Our results suggest that color determinants of surface stratification cannot be reduced to simple lightness contrast but must be weighted as a function of the natural lightness of hues. These results entail some influence of color harmony. It has been found that colors combined in pairs appear pleasant to most people if their lightnesses are proportional to the lightnesses of their underlying hues $^{55,56}$. This rule was modified when the NCS system was used to specify colors, and whiteness and blackness were considered more relevant than lightness, so that in bi-color combinations, the whiteness of the two colors must conform the ratios of the natural lightness of their hue to appear agreeable to most people 24,27 . Furthermore, the natural lightness of hues is important in the appearance of fluorescence in colors, as the luminance over which they appear fluorescent depends on the natural lightness of the hue: the higher the natural lightness, the higher the actual luminance for the fluorescence appearance ${ }^{28}$. Fluorescence may therefore also have a role in perceived depth stratification.

\section{REFERENCES}

[1] Gage J. Colour and culture. Practice and meaning from antiquity to abstraction. Oakland, CA: University of California Press; 1993.

[02] Kemp M. The science of art: optical themes in western art from Brunelleschi to Seurat. New Haven: Yale University; 1992.

[03] Kistho B N. The colour stereoscopic effect. Vision Res 1965; 5:313-329. 
[4] Campbell M C, Simonet P. Video monitoring of the principal ray of a Maxwellian view for the measurement of optical aberrations, the Stiles-Crawford effect, retinal resolution, and for investigating color vision. Appl Optics 1990; 29(10):1420-6. doi: 10.1364/AO.29.001420

[5] Ye M, Bradley A, Thibos LN, Zhang X. Interocular differences in transverse chromatic aberration determine chromostereopsis fo small pupils. Vision Res 1991;31:1787-1796. doi: $10.1016 / 0042-6989(91) 90026-2$

[6] Sundet J M. Effects of colour on perceived depth. Scand J Psych. 1978;19:133-143.

[7] Bodè DD. Chromostereopsis and chromatic dispersion. Am J of Opt \& Physiol Opt. $1986 ; 63: 859-866$.

[8] Dunnewold C J W. On the Campbell and Stiles-Crawford effects and their clinical importance. Institute for Perception. The Netherlands National Defence Research Organisation RVOTNO, Utrecht; 1964.

[9] Faubert Y. Seeing depth in colour: More than just what meets the eye. Vision Res 1994;34(9):1165-1186.

[10] de Weert C M. Colour contours and stereopsis. Vision Res 1979;19(5):555-

564. http://dx.doi.org/10.1016/0042-6989(79)90141-X

[11] Thompson P, Stone R. Chromostereopsis: the relative contributions of colour and luminance to perceived depth. Perception 1993; 22(Suppl.):9-10.

[12] Thompson P, May K, Stone R. Chromostereopsis: A multicomponent effect? Displays 1993;14(4):227-233. doi:10.101670141-9382(93990093.

[13] Masin S C. Luminance determinants of perceived surface stratification in two-dimensional achromatic transparent patterns. Perception 2000;29:853-861. 
[14] Chen I, Lin J. Quantitative assessment of the advancing/receding and the expansion/constriction effects of colours. Proc AIC Colour 05, 10th AIC Congress, Granada 2005,1481-1484.

[15] da Pos O, Straulino E. Apparent stratification of transparent figures depends on the contrast at the borders. Proc CIE Expert Symposium on Visual Appearance 19-20 Oct 2006. 2007:1-6.

[16] da Pos O, Devigili A, Giaggio F, Trevisan G. Color contrast and stratification of transparent figures. Jap Psych Res, Special issue: Optical illusions, Blackwell Publishing Asia , 2007,49 (1):68-78. doi: 10.1111./j.1468-5884.2007.00333.x.

[17] Egusa H. Effects of brightness, hue, and saturation on perceived depth between adjacent regions in the visual field. Perception 1983;12:167-175. Doi: 10.1068/p120167

[18] Albers J. Interaction of color. New Haven: Yale University Press; 2013.

[19] da Pos O. Natural lightness of hues and chromostereopsis. Col Dynam. '88, 2-6 Nov. 1988, Budapest, Abstracts p. 52.

[20] Koenderink J J, Van Doorn A, Albertazzi L, Wagemans J. Relief articulation techniques. Art \& Perception 2015;3:151-171. doi: 10.1163/22134913-00002032

[21] Itten J. Kunst der Farbe. Ravensburg: Otto Maier Verlag; 1961.

[22] Spillmann W. The concept of lightness ratio of hues in colour combination theory. Mondial Couleur 1985. AIC, Montecarlo. p. 1-6.

[23] Griffin LD. Optimality of the basic colour categories for classification. J Roy Soc Interf. . 2006;3:71-85. doi:10.1098/rsif.2005.0076 
[24] da Pos O. The pleasantness of bi-colour combinations of the four unique hues In: $\mathrm{H}$ Arnkil, E Hamalainen, eds. Aspects of Colour. Helsink: UIAH University of Arts and Designi 1995;p. 164-174.

[25] da Pos O. When do colours become fluorent? In: J L Caivano, H-P Struck, eds, AIC 2004 Color and Paints. Proc AIC Interim Meeting, Porto Alegre, Brazil, 2004:3-8.

[26] da Pos O, Dal Mas G, Stelluto F. Aesthetic quality of colour combinations. Óbuda University e-Bulletin 3(1); 2012.

[27] da Pos O, Fabrizi G. An experimental study of colour combination theory. Proc AIC Intern Meeting ‘Colour and Environmental Design', Winterthur, VI 1998;1-6.

[28] da Pos O, Sponga M. Fluorescence thresholds for some reddish colors. Proc. SPIE 4421, The 9th AIC Congress, 2002. doi: 10.1117/12.464723

[29] Mausfeld R. Colour as part of the format of different perceptual primitives: the dual coding of colour. In R Mausfeld, D Heyer, eds, Colour Perception, Ch. 13. Oxford: Oxford University Press; 2003:381-430.

[30] Gilchrist A, Kossyfidis C, Agostini T, Li X, Bonato F, Cataliotti J, Spehar B, Annan V, Economou E. An anchoring theory of lightness perception. Psych Rev. 1999;106(4):795-834. PMID:10560329

[31] Kanizsa G. Organization in vision. Santa Barbara, CA: Praeger; 1979.

[32] Michotte A, Thinès G, Crabbé G. Les complements amodaux des structures perceptives. Louvain: Publications Universitaires; 1964. Trans. in Thinès G, Costall A, Butterworth G, eds. Michotte's experimental phenomenology of perception. Hillsdale, NJ: Erlbaum; 1991:140-168. 
[33] Koffka K. Principles of gestalt psychology. New York: Harcourt Brace;1935.

[34] Albertazzi L. Towards a neo-Aristotelian theory of continua: Elements of an empirical geometry. In L Albertazzi, ed. Unfolding perceptual continua. Amsterdam: Benjamins Publishing Company; 2002:29-37.

[35] Brentano F. Philosophical investigations on space, time and the continuum. London: Croom Helm; 1988.

[36] Hård A, Sivik L. A theory of colors in combination - A descriptive model related to the NCS color order system. Col Res Appl. 2001;26:4-28.

[37] NCS Natural Colour System ${ }^{\circledR C}$ C. Colour Atlas 2nd Edition. SIS SS 19102:2004; Stockholm: Skandinaviska Farginstitutet AB, 2007.

[38] Hering E. Grundzüge der Lehre vom Lichtsinn. Springer-Verlag; 1920. (Eng. Transl. by L M Hurvich, D Jameson, Outlines of a theory of the light sense. Cambridge, MA: Harvard University Press; 1964.

[39] Kuehni R. Variability in unique hue selection: a surprising phenomenon. Col Res Appl $2003 ; 29(2): 158-162$.

[40] Hirschler R. Visual and instrumental evaluation of whiteness and yellowness. In: Gulrajani ML, ed, Colour measurement: Principles, advances and industrial applications. Chapter 4. Cambridge, UK: Woodhead Publishing, 2010:pp.88-124. Doi: 10.1533/9780857090195.1.88

[41] Derefeldt G, Christer S. Transformation of NCS data into CIELAB colour space. Col Res Appl. $1986 ; 11(2): 1-152$.

[42] CIE (2011) S 017/E:2011 ILV: Inernational Lighting Vocabulary. http://cie.co.at/publications/ilv-international-lighting-vocabulary-2nd-edition 
[43] Delboeuf J. Sur une nouvelle illusion d'optique [On a new optical illusion]. Bull Acad Roy Belg. 1892;24(3d serie):545-558. (Reprinted in Rev Scientif, 1893;51:237-241)

[44] Pinna B, Brelstaff G, Spillmann L. Surface color from boundaries: a new 'watercolor' illusion. Vis Res. 2001;41(20):2669-2676.

[45] Gerardin P, Devinck F, Dojat M, Knoblauch K. Contributions of contour frequency, amplitude, and luminance to the watercolor effect estimated by conjoint measurement. $J$ Vis. (2014;14(4):9,1-15. http://www. journalofvision.org/content/14/4/9, doi:10.1167/14.4.9.

[46] Paggetti G, Menegaz G, Paramei G. Color naming in Italian language. Col Res Appl. 2015;41(4):402-415. https://doi.org/10.1002/col.21953

[47] Boynton R, Olson X. Locating basic colors in the OSA space. Col Res Appl 1987; 12(2):94105.

[48] Sturges J, Whitfield TWA. Salient Features of Munsell Colour Function of Monolexemic Naming Latencies. Vis Res 1997;37(3):307-313.

[49] Mylonas D, MacDonald L. Online Colour Naming Experiment Using Munsell Samples. Conference paper, 2010. https://www.researchgate.net/publication/258831962_Online_Colour_Naming_Experiment_Using_ Munsell_Samples/link/00b7d5290920b18a0f000000/download<smiles>[AlH2]</smiles>
https://books.google.it/books?id=hcq_40I_7egC\&pg=PA242\&lpg=PA242\&dq=red+usually+appear $\mathrm{s}+$ closer+to + the + observers\&source $=$ bl\&ots $=$ qW2Jz79czW\&sig=ACfU3U0QpKkn1tQdf5FxWzPq wxXW0O5JFA\&hl=it\&s\%20a=X\&ved=2ahUKEwiP$\# \mathrm{v}=$ onepage \&q=red $\%$ 20usually $\%$ 20appears $\% 20$ closer $\% 20$ to $\% 20$ the $\% 20$ observers $\& \mathrm{f}=$ false 
[51] Kaiser PK. The Helmholtz-Kohlrausch effect. Col Res Appl 1995; 10: 187.

[52] Bimler D, Paramei D, Izmailov CA. Hue and saturation shifts from spatially induced blackness. J Opt Soc Am. A, 2009;26:163-172.

[53] Palmer SE, Schloss KB. An ecological valence theory of human color preference. PNAS. May 11,$2010 ; 107(19): 8877-8882$.

[54] Koenderink J J, Van Doorn A, Albertazzi L, Wagemans J. Hue contrast and the sense of space. I- Percep. 2015b; 6(2):67-85. Doi: dx.doi.org/10.1068/i0XXX

[55] Abbott A G. Harmonies and discords. In: The color of life. New York: McGraw-Hill Book Comp. Inc.1947; 106-110.

[56] Müller A. Die moderne Farbenharmonielehre. Winterthur: Chromos; 1948. 

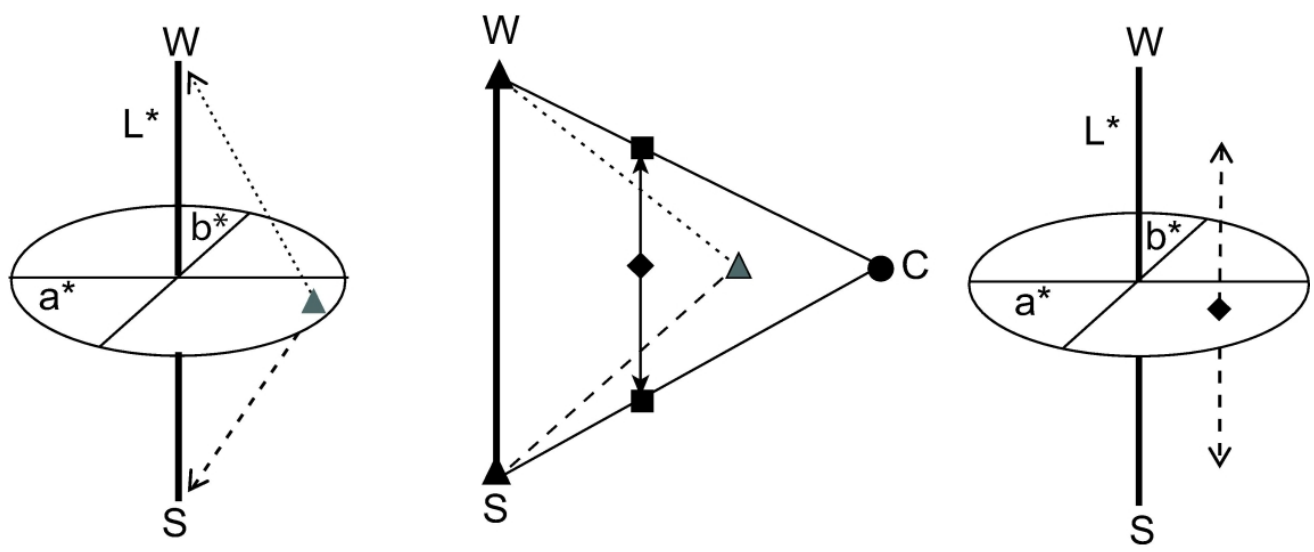

FIGURE 1. The whiteness (W) and blackness (S) of the given color represented in the NCS by the central gray triangle (central figure) can be increased or decreased along the two intervals given-color $\square$ white (dotted line) and given-color $\square$ black (broken line). At left: the same variations can be represented in a CIELAB L*a*b* color space by lines connecting the given-color to $L^{*}=100$ (white) and to $L^{*}=0$ (black).

These involve variations of CIELAB L* and C*. At right: Variations in $L^{*}$ at constant chroma are exhibited in the CIELAB system.

$162 \times 67 \mathrm{~mm}(600 \times 600 \mathrm{DPI})$ 


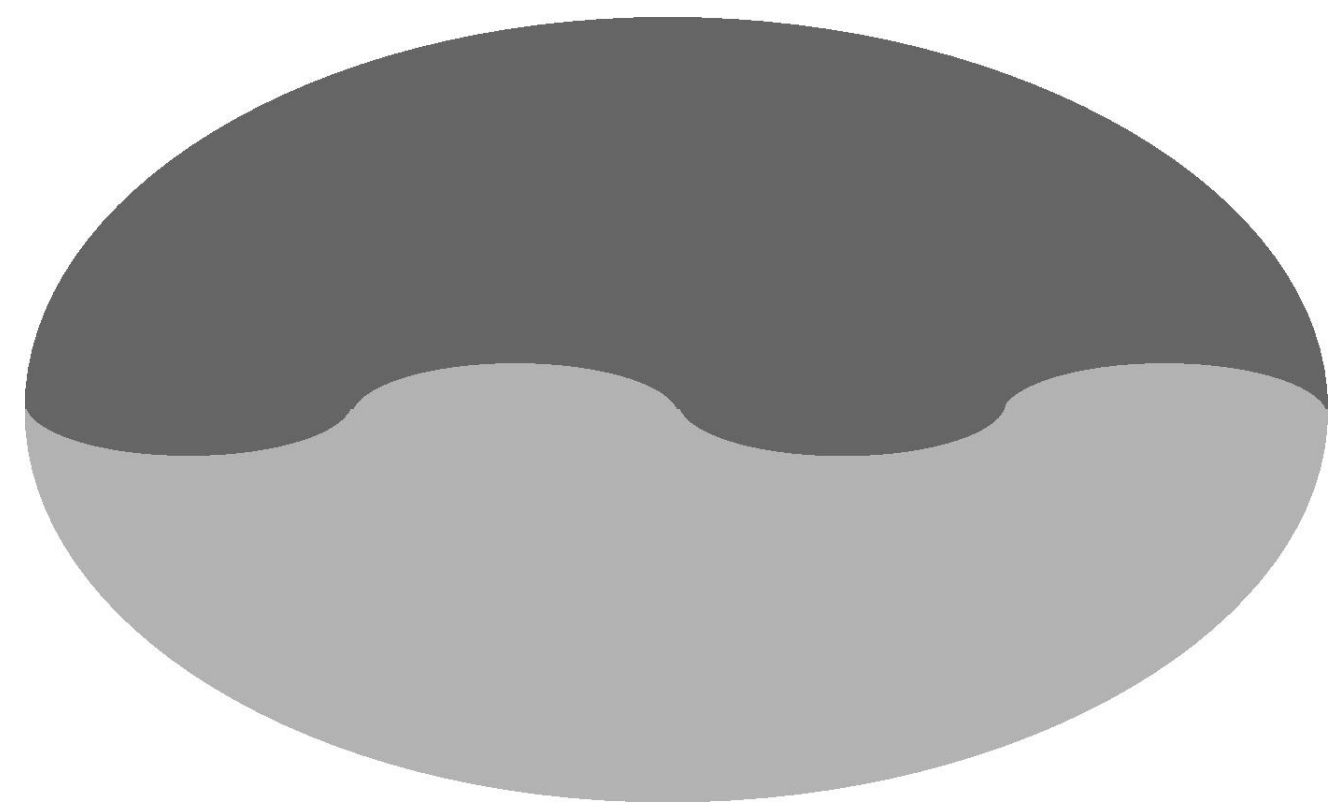

FIGURE 2. An example of the stimuli used at the beginning of each trial. The stimuli shown are for the whiteness/blackness adjustment in which the high chroma colors variants were used. The same stimulus structure was used for adjustments in lightness only but with less chromatic colors. The color of one sector was fixed and the other adjustable (randomly chosen from trial to trial).

\section{$59 \times 35 \mathrm{~mm}(600 \times 600 \mathrm{DPI})$}




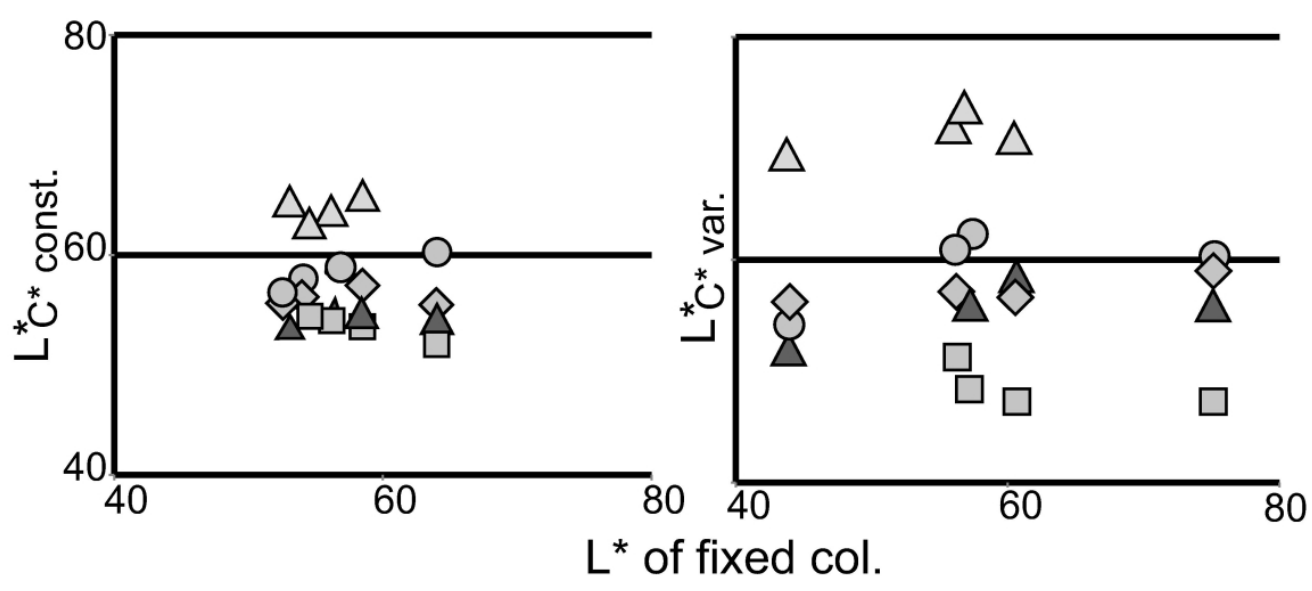

FIGURE 3. Adjusted L*in the lightness adjustment task at constant chroma (left) and the whiteness adjustment task with adjusted chroma (right) as a function of the $L^{*}$ of fixed colors. Labels R P B G Y refer to the fixed colors, which are different in the two parts of the experiment; the symbols show the $L^{*}$ of the adjusted colors (square: red; dark triangle: purple; diamond: blue; circle: green; light triangle: yellow).

$163 \times 71 \mathrm{~mm}(600 \times 600 \mathrm{DPI})$ 


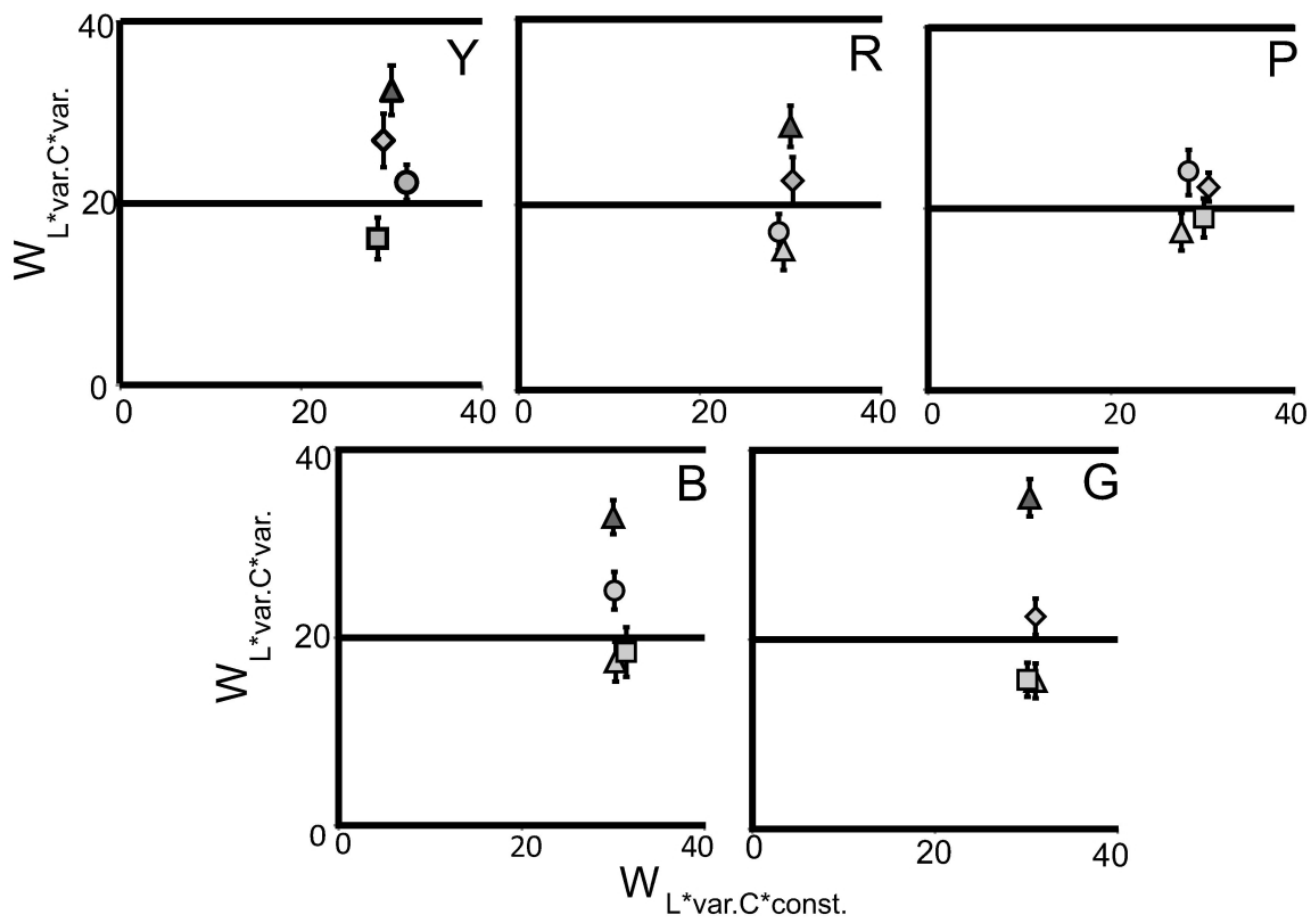

FIGURE 4. Whiteness of colors adjusted in $L^{*}$ and $C^{*}(W)$ as a function of the Whiteness of colors fixed in $L^{*}$ with $C^{*}(W)$. In the second case, variations in $L^{*}$ with $C^{*}$ constant imply some small variations in $W$. Symbols show the tested colors (square: red; dark triangle: purple; diamond: blue; circle: green; light triangle: yellow), and the label in the background refers to the fixed color. Error bars $=\mathrm{SE}$.

$152 \times 107 \mathrm{~mm}(600 \times 600 \mathrm{DPI})$ 


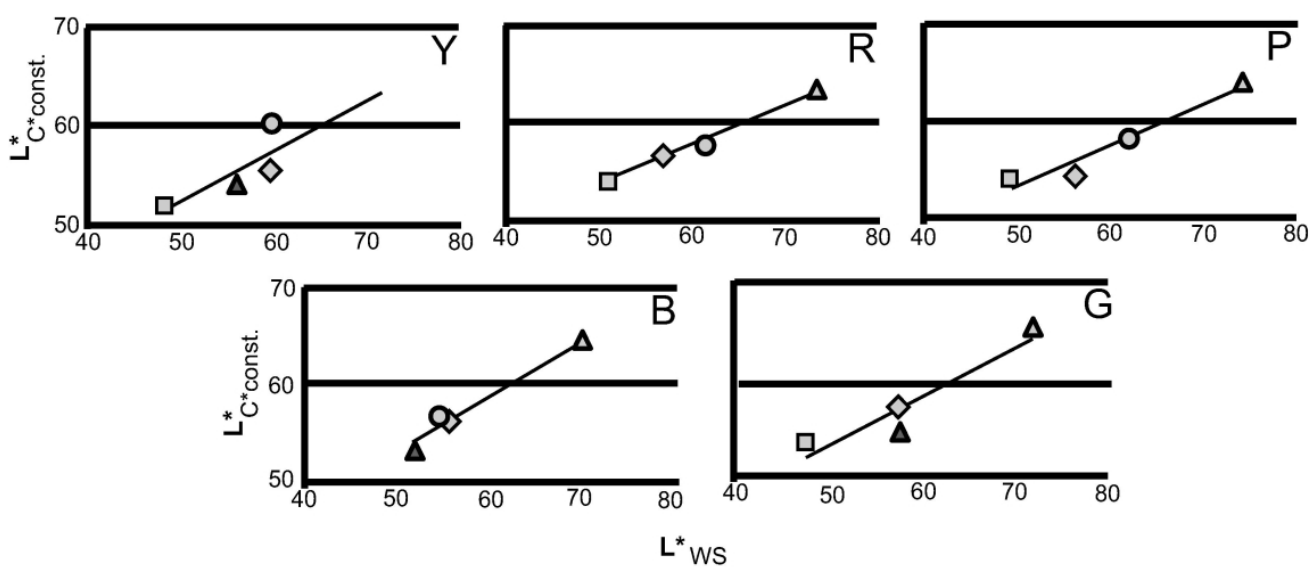

FIGURE 5. The mean L* of colors adjusted in lightness at constant chroma as a function of the mean $L^{*}$ of colors adjusted in Whiteness or Blackness (that is, L* with $C^{*}$ adjusted). The labels in the background represent the hue of the fixed colors. The color of the symbols represents the adjusted color (square: red; dark triangle: purple; diamond: blue; circle: green; light triangle: yellow).

$$
149 \times 64 \mathrm{~mm}(600 \times 600 \mathrm{DPI})
$$



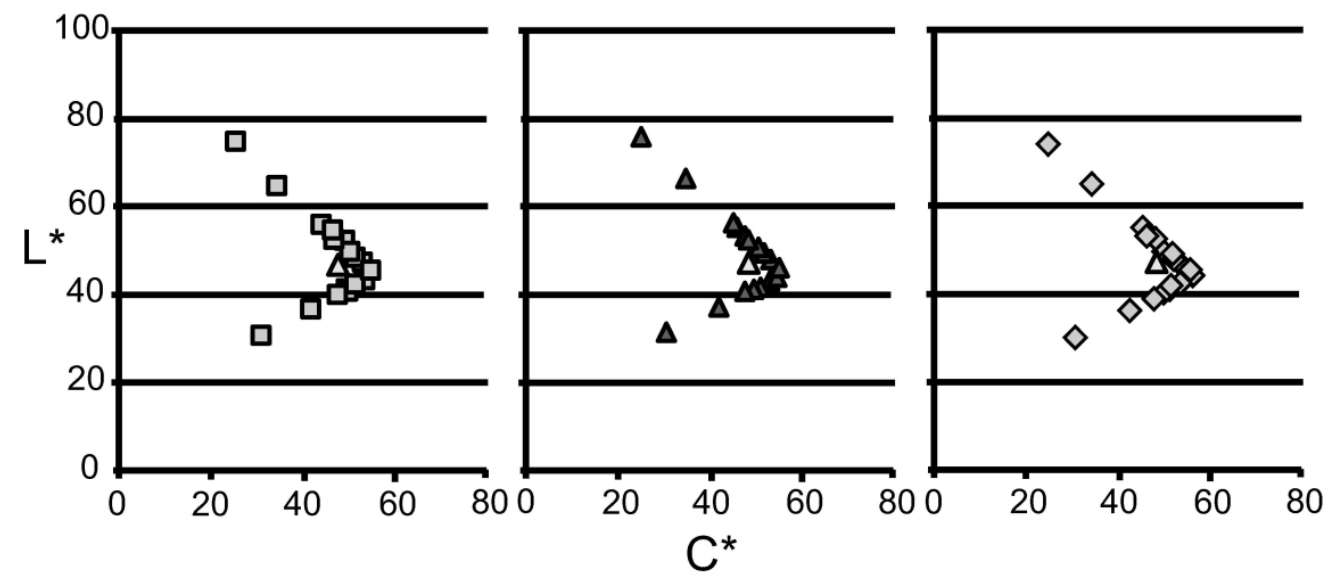

FIGURE 6. Plot of $L^{*}$ as a function of $C^{*}$ of colors adjusted in WS ( $L^{*}$ and $C^{*}$ ). In this example the fixed color is yellow (light triangle), and the adjusted ones are red (squares), purple (dark triangles), and blue (diamonds).

\section{$159 \times 99 m m(600 \times 600$ DPI $)$}




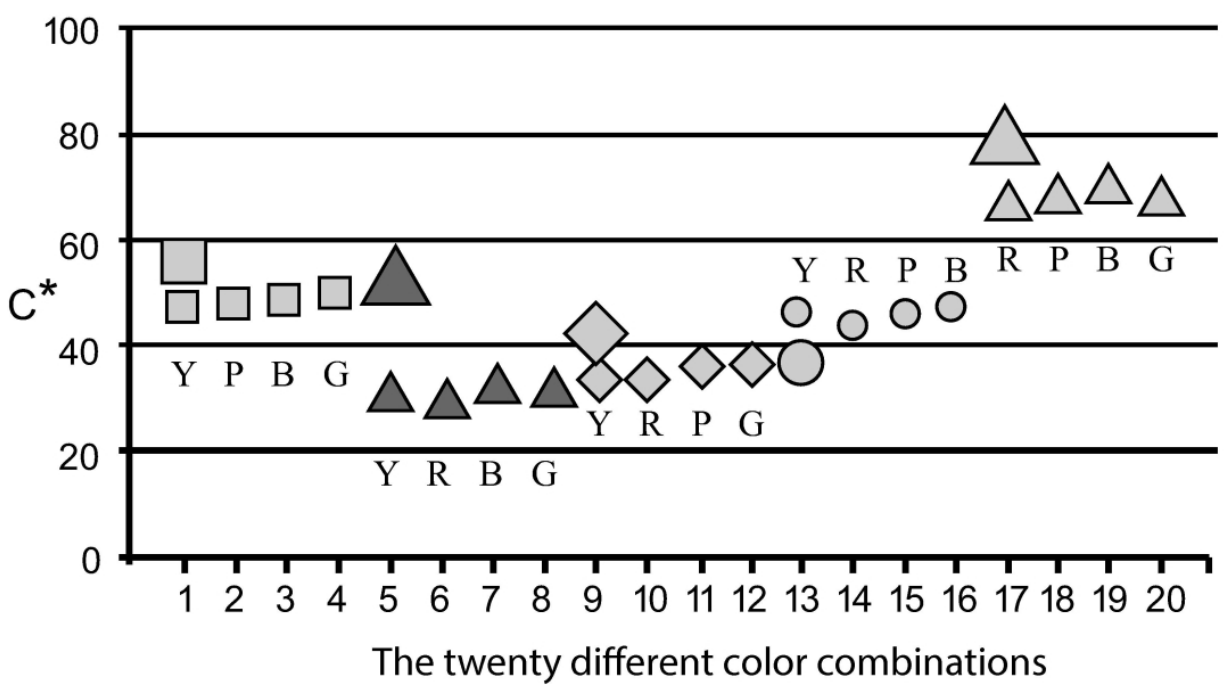

FIGURE 7. Effective mean variation in chroma due to adjustment in whiteness/blackness for each color combination. Large symbols: chroma of the starting colors. Each small square represents the same adjustable color in combination with the other four colors, which are fixed. For instance, red circles represent the final chroma of the red adjusted in whiteness/blackness in the four different combinations in which it is presented.

$148 \times 77 \mathrm{~mm}(600 \times 600 \mathrm{DPI})$ 

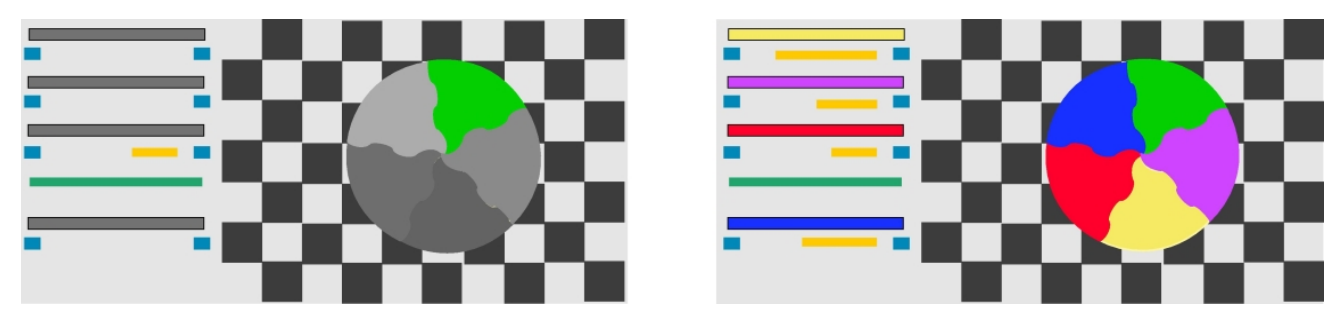

FIGURE 8. An example of the stimuli used in Experiment 2.

$160 \times 35 \mathrm{~mm}(600 \times 600 \mathrm{DPI})$ 


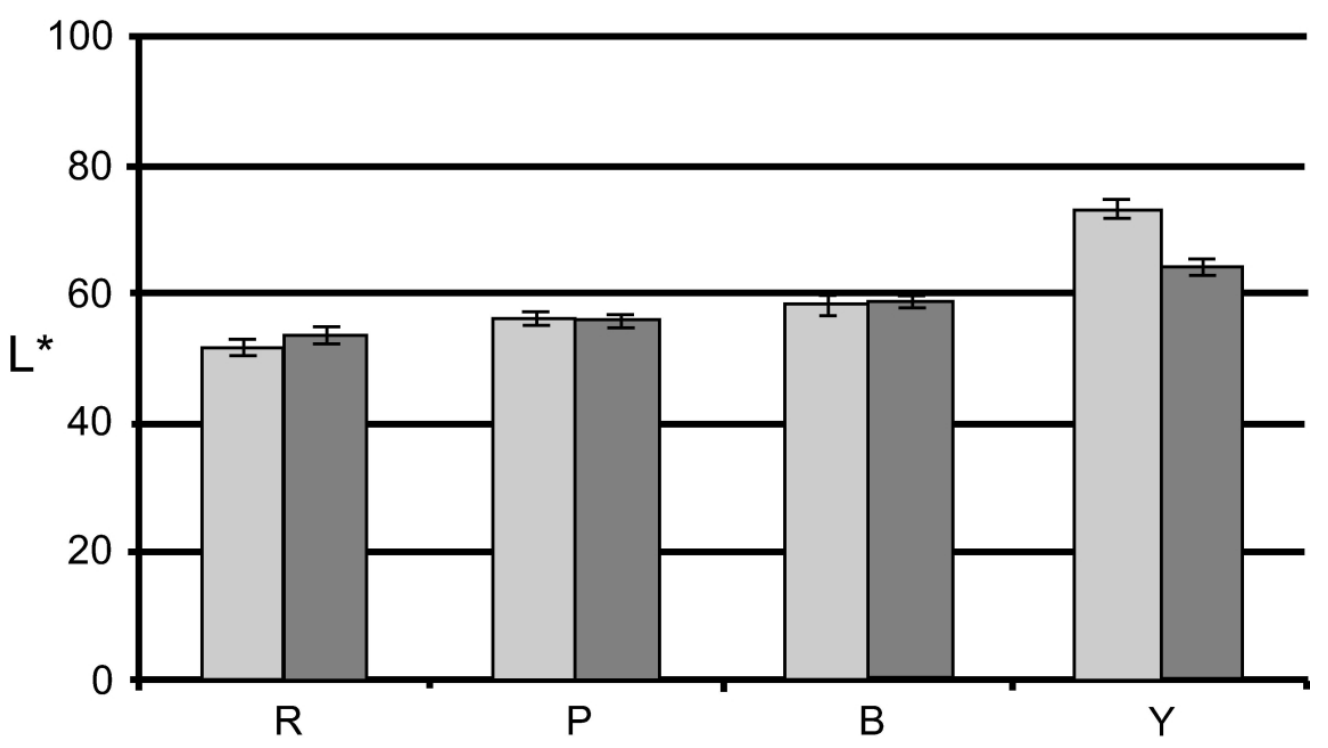

FIGURE 9. Mean adjusted L* of the four adjusted colors. Green was fixed. Light bars: whiteness adjustment (both $L^{*}$ and $C^{*}$ adjusted) ; Dark bars: Lightness adjustments ( $L^{*}$ with constant $C^{*}$ ) as a function of the four adjusted colors .

$154 \times 92 \mathrm{~mm}(600 \times 600 \mathrm{DPI})$ 


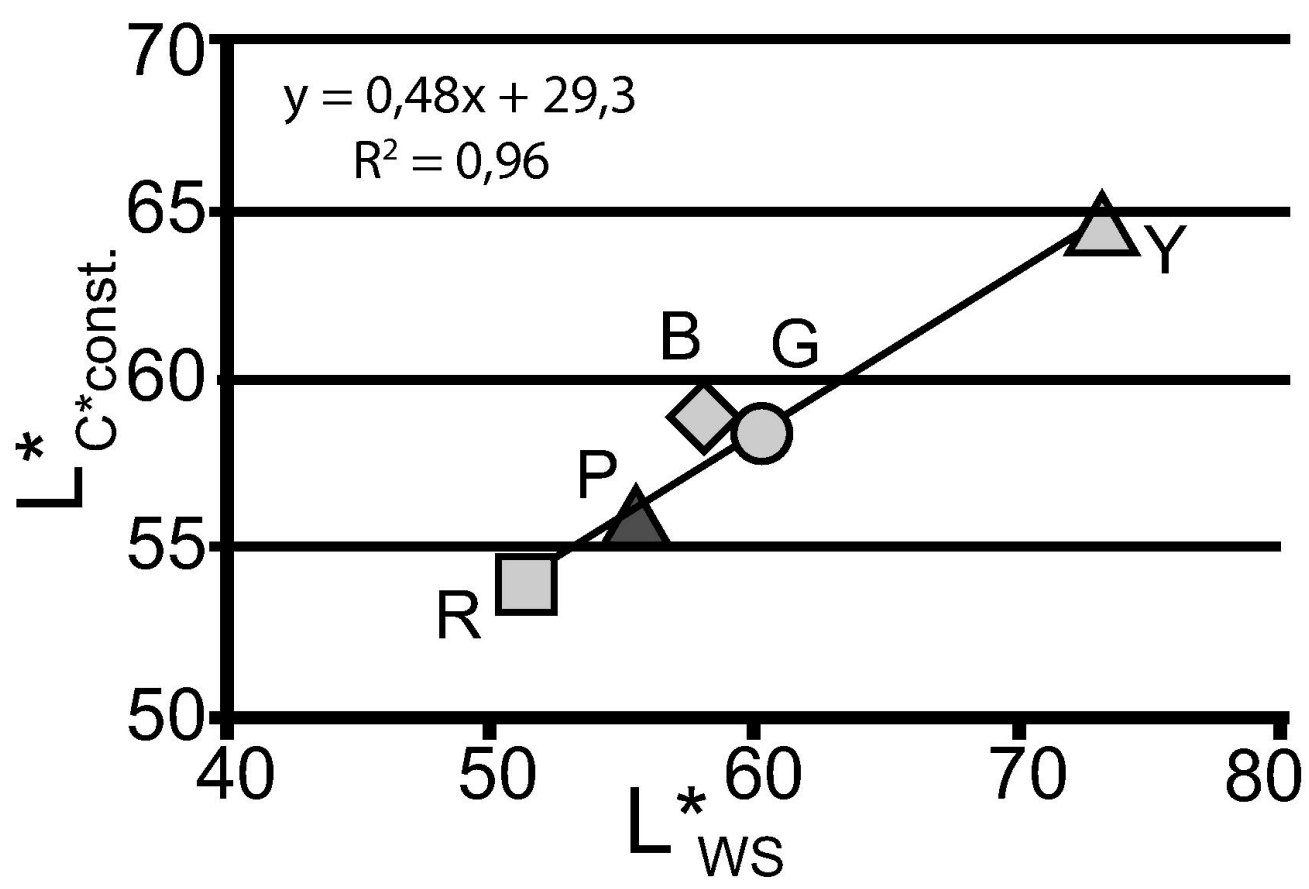

FIGURE 10. The mean $L^{*}$ of colors adjusted in lightness as a function of the mean $L^{*}$ of colors adjusted in whiteness/blackness. Green was always fixed.

$71 \times 48 \mathrm{~mm}(600 \times 600 \mathrm{DPI})$ 


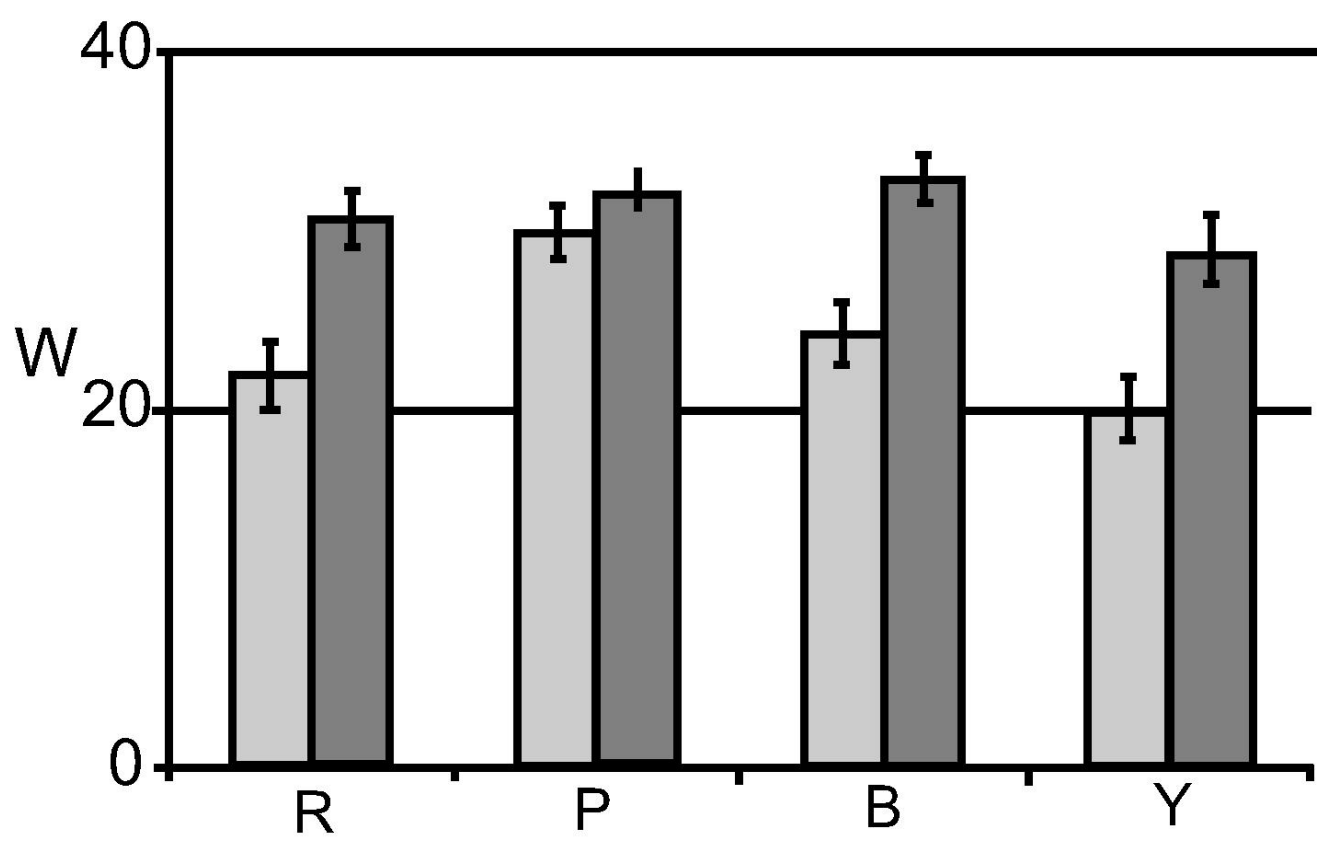

FIGURE 11. Mean adjusted W of the four adjusted colors. Green was fixed. Light bars: adjustment in whiteness (adjusted $\mathrm{L}^{*}$ and $\mathrm{C}^{*}$ ); dark bars: adjustment in lightness ( $\left.\mathrm{L}^{*}\right)$ with constant $\mathrm{C}^{*}$.

$59 \times 38 \mathrm{~mm}(600 \times 600$ DPI $)$ 


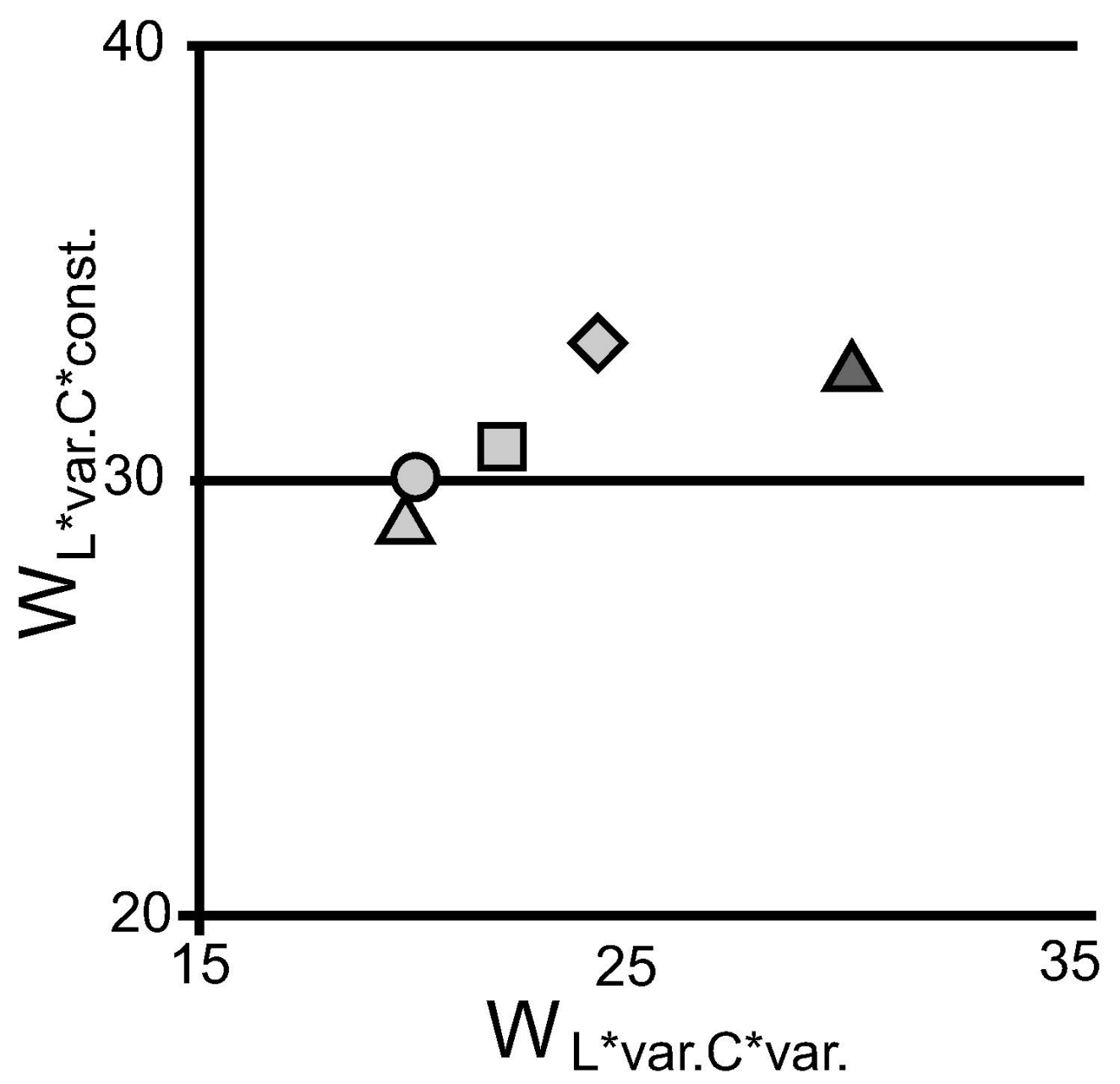

FIGURE 12. Whiteness of colors adjusted in $L^{*}$ and $C^{*}\left(W_{C^{*} v a r}\right)$ as a function of the Whiteness of colors adjusted in $L^{*}$ with $C^{*}$ fixed ( $\left.W_{C * \text { const }}\right)$. Square: red; dark triangle: purple; diamond: blue; circle: green; light triangle: yellow.

$62 \times 60 \mathrm{~mm}(600 \times 600 \mathrm{DPI})$ 


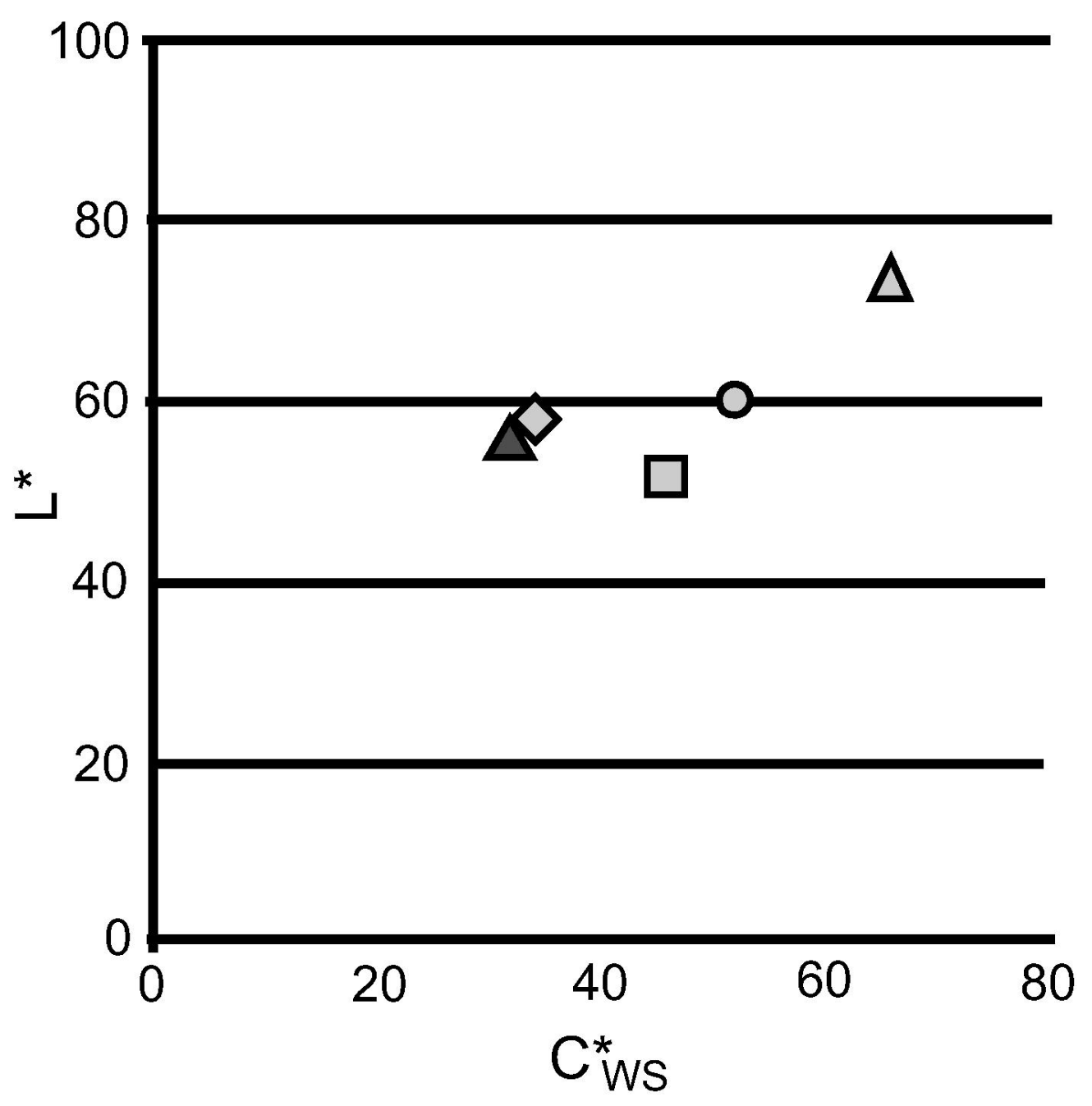

FIGURE 13. The adjusted $L^{*} s$ are plotted as a function of $C^{*}$ for color adjusted in $W\left(L^{*}+C^{*}\right)$. Green is fixed. Error bars (SE) are smaller than the size of symbols.

$59 \times 60 \mathrm{~mm}(600 \times 600 \mathrm{DPI})$ 


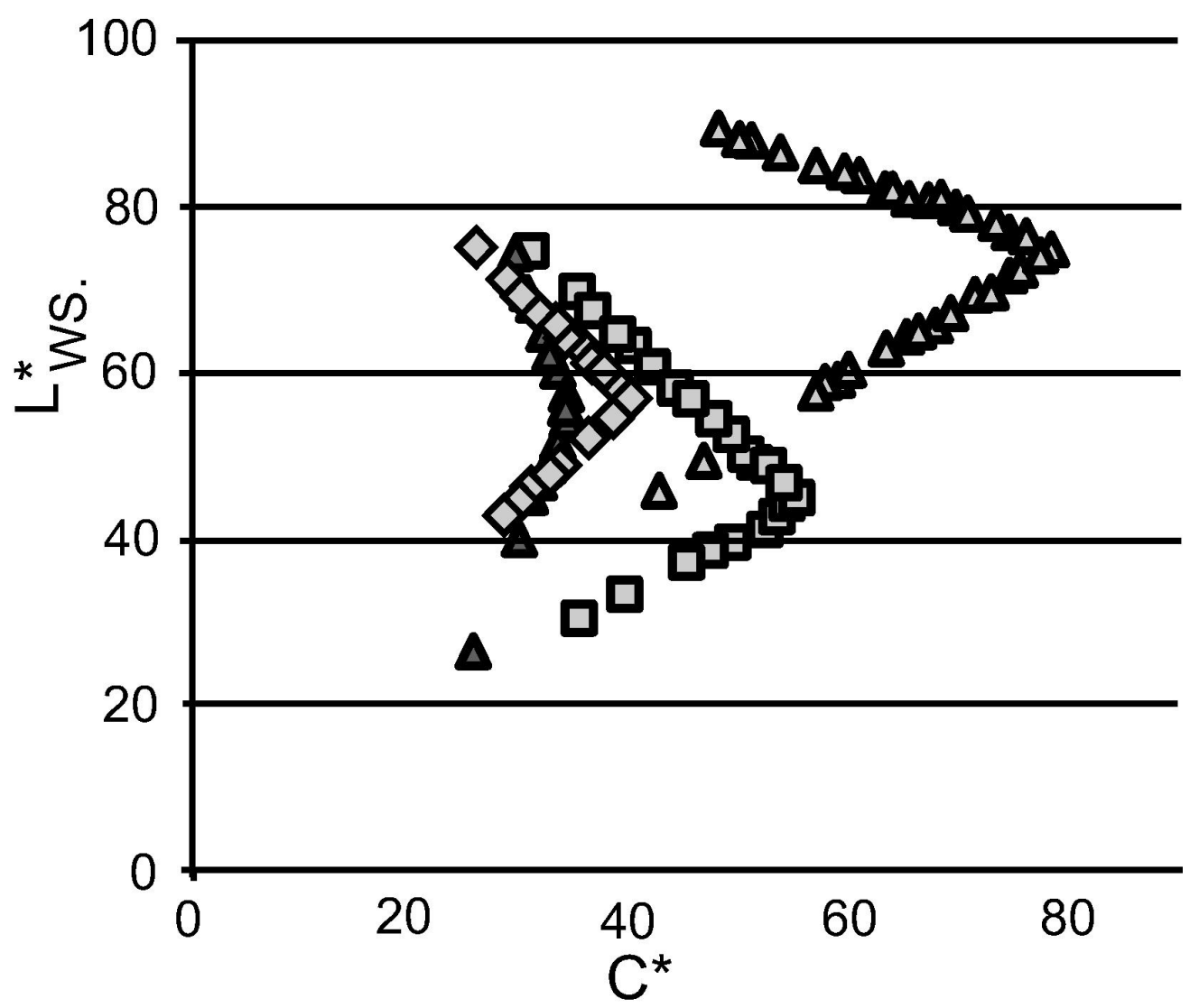

FIGURE 14. Plot of L*WS (together with $C^{*}$ which was varied accordingly) as a function of C* of colors adjusted in WS (specifically: $L^{*}+C^{*}$ ). The graph shows all the adjustments performed by the 45 participants in Experiment 2 relative to the four adjusted colors. Light triangles: yellow, diamonds: blue; dark triangles: purple; squares: red.

$70 \times 59 \mathrm{~mm}(600 \times 600 \mathrm{DPI})$ 
TABLE 1. CIELAB specifications of the high (left) and low (right) chroma colors two of which were presented at the beginning of the experimental trials.

\begin{tabular}{|c|c|c|c|c|c|c|}
\cline { 2 - 7 } \multicolumn{1}{c|}{} & \multicolumn{3}{c|}{ high chroma colors } & \multicolumn{3}{c|}{ low chroma colors } \\
\hline Color & L* $^{*}$ & $\mathrm{a}^{*}$ & $\mathrm{~b}^{*}$ & $\mathrm{~L}^{*}$ & $\mathrm{a}^{*}$ & $\mathrm{~b}^{*}$ \\
\hline Y & 75.1 & 8.3 & 79 & 64 & 3.9 & 38.2 \\
R & 43.9 & 51.5 & 21.7 & 53.3 & 27 & 9.5 \\
P & 56.5 & 24.8 & -24.4 & 54.3 & 19.3 & -18 \\
B & 57 & -24.4 & -32.1 & 56.2 & -13.8 & -21.3 \\
G & 60.7 & -48.6 & 19.7 & 58.5 & -26.2 & 10.7 \\
\hline
\end{tabular}


TABLE 2. Results from experiment 1. Whiteness Adjustment: $L^{*}{ }_{w s}=$ lightness value resulting from the adjusted whiteness $\left(\mathrm{W}_{\mathrm{ws}}\right)$ at coplanarity; Whiteness values (approximate) resulting from whiteness adjustment at coplanarity (these values are approximate and were derived using a personal dataset). $\mathrm{C}^{*}$ ws $=$ chroma value resulting from the adjusted whiteness value $\left(\mathrm{W}_{\mathrm{ws}}\right)$ at coplanarity; Lightness Adjustment: $L^{*}{ }_{L^{*}}=$ values of lightness attained in the lightness adjustment with constant chroma $C^{*} ; W_{L^{*}}=$ value of Whiteness derived from the adjusted value of lightness $L^{*}{ }^{*}$ and the fixed chroma value (approximate, see text); $C^{*} L^{*}=$ resulting $C^{*}$ when $L^{*}$ was adjusted at constant $C^{*}$ (due to the adjustment process, $C^{*}$ was not perfectly constant). Values are shown for each color pair: the first number denotes the fixed color, the second number the adjustable color $(1=Y ; 2=R ; 3=P ; 4=B ; 5=G)$.

\begin{tabular}{ccccccccccccc}
\hline $\begin{array}{c}\text { color } \\
\text { pair }\end{array}$ & \multicolumn{2}{c}{$\mathrm{L}^{*}$ ms } & \multicolumn{2}{c}{$\mathrm{W}_{\mathrm{WS}}$} & \multicolumn{2}{c}{$\mathrm{C}^{*}$ WS } & \multicolumn{2}{c}{$\mathrm{L}^{*} \mathrm{~L}^{*}$} & \multicolumn{2}{c}{$\mathrm{W}_{\mathrm{L}^{*}}$} & \multicolumn{3}{c}{$\mathrm{C}^{*}{ }^{*}$} \\
\hline 12 & 47.2 & 1.3 & 16.3 & 1.6 & 48.21 & 1.0 & 51.9 & 1.1 & 28.5 & 1.0 & 28.41 & 0.1 \\
13 & 55.8 & 1.4 & 32.4 & 1.8 & 29.03 & 0.7 & 54.1 & 0.9 & 30.0 & 1.0 & 26.36 & 0.0 \\
14 & 59.5 & 1.5 & 26.9 & 2.4 & 33.87 & 1.0 & 55.5 & 1.1 & 29.1 & 1.2 & 25.35 & 0.0 \\
15 & 59.6 & 1.1 & 22.3 & 1.5 & 45.45 & 0.8 & 60.3 & 1.0 & 31.7 & 1.1 & 28.29 & 0.0 \\
21 & 70.2 & 1.4 & 15.1 & 1.6 & 66.83 & 1.5 & 64.4 & 0.9 & 29.2 & 1.3 & 38.37 & 0.0 \\
23 & 51.9 & 1.5 & 28.5 & 1.7 & 27.49 & 0.8 & 53.3 & 0.8 & 30.0 & 0.9 & 26.36 & 0.0 \\
24 & 55.8 & 1.5 & 22.6 & 2.0 & 33.65 & 0.9 & 56.4 & 1.1 & 30.3 & 1.2 & 25.35 & 0.0 \\
25 & 54.8 & 1.2 & 17.1 & 1.3 & 43.53 & 1.0 & 56.7 & 1.1 & 28.7 & 1.2 & 28.29 & 0.0 \\
31 & 73.2 & 1.0 & 17.4 & 1.6 & 68.40 & 1.1 & 63.2 & 1.0 & 27.7 & 1.6 & 38.37 & 0.0 \\
32 & 50.7 & 1.2 & 19.0 & 1.8 & 47.99 & 1.0 & 54.2 & 0.8 & 30.1 & 0.9 & 28.62 & 0.0 \\
34 & 56.8 & 1.1 & 22.3 & 1.3 & 35.37 & 0.6 & 56.6 & 0.9 & 30.6 & 0.9 & 25.36 & 0.0 \\
35 & 61.3 & 1.1 & 24.1 & 1.8 & 45.56 & 0.9 & 57.7 & 0.8 & 28.5 & 1.0 & 28.29 & 0.0 \\
41 & 74.1 & 0.9 & 17.4 & 1.6 & 69.94 & 1.2 & 63.9 & 1.5 & 30.3 & 2.1 & 38.35 & 0.0 \\
42 & 48.9 & 1.4 & 18.5 & 2.1 & 48.26 & 1.2 & 54.0 & 1.5 & 31.4 & 1.4 & 28.62 & 0.0 \\
43 & 56.1 & 1.1 & 32.8 & 1.3 & 30.34 & 0.5 & 54.4 & 1.0 & 30.0 & 1.0 & 26.36 & 0.0 \\
45 & 61.9 & 0.9 & 25.0 & 1.5 & 47.22 & 0.8 & 58.4 & 0.9 & 30.1 & 1.0 & 28.29 & 0.0 \\
51 & 71.8 & 1.2 & 15.6 & 1.3 & 67.70 & 1.2 & 65.3 & 1.1 & 31.0 & 1.6 & 38.36 & 0.0 \\
52 & 47.3 & 1.0 & 15.8 & 1.3 & 49.78 & 0.8 & 53.6 & 0.8 & 30.1 & 1.1 & 28.62 & 0.0 \\
53 & 57.6 & 1.2 & 35.0 & 1.5 & 29.85 & 0.6 & 54.6 & 1.2 & 30.4 & 1.4 & 26.35 & 0.0 \\
54 & 57.4 & 0.8 & 22.4 & 1.4 & 36.56 & 0.5 & 57.3 & 0.8 & 31.0 & 1.0 & 25.36 & 0.0 \\
\hline
\end{tabular}

